Article

\title{
Design for Visual Quality Enhancement of Artificial Infrastructure Facilities: An Application to Electricity Pylons
}

\author{
Luca Di Angelo ${ }^{1}\left(\mathbb{D}\right.$, Francesco Gherardini $^{2}{ }^{2} \mathbb{C}$, Paolo Di Stefano ${ }^{1}$ and Francesco Leali ${ }^{2}$ \\ 1 Department of Industrial and Information Engineering and Economics, University of L'Aquila, \\ 67040 L'Aquila, Italy; luca.diangelo@univaq.it (L.D.A.); paolo.distefano@univaq.it (P.D.S.) \\ 2 Department of Engineering “Enzo Ferrari”, University of Modena, 41125 Modena, Italy; \\ francesco.leali@unimore.it \\ * Correspondence: francesco.gherardini@unimore.it
}

Received: 31 December 2019; Accepted: 25 January 2020; Published: 7 February 2020

Featured Application: A systematic method to design new tower-like structures with an enhanced visual impact quality is proposed. The method is applied to the design of electricity pylons, which are very critical structures due to their visual impact on landscape and on citizens' perception. During all the design process-from conceptual to detailed design phases-regulatory, industrial feasibility, safety, and social components are considered key requirements. The method can be easily applied to other pylons, at the service of renewable energy production and distribution, and telecommunications.

\begin{abstract}
Background: The visual impact of artificial infrastructures on natural landscapes generates a common negative perception in public opinion. However, as in the case of electrical energy, the increasing demand for power supply and its need for capillary distribution require the installation of new lines, commonly overhead lines with tall tower-like pylons. In most countries, this situation is faced with many attempts of solutions, as participatory workshops and design contests. Nevertheless, the solutions are usually not further developed into real structures due to many limitations (e.g., regulatory, safety, lack of feasibility). (2) Methods: This paper presents a systematic method for the design of tower-like pylons (e.g., electric ones) able to improve the visual quality on the landscape areas in which they will be installed. The method identifies a design strategy that advantageously exploits the inevitable visual impact of pylons on the landscape by integrating the symbolic morphology and the topologically optimized pylon structure from the earliest design phases. (3) Results: The resulting structure is designed in three steps. First, a concept is morphologically developed by integrating symbolic references to the landscape, environment, or cultural society. Second, the concept is topologically optimized, by reducing the structural weight and its visual impact, and respecting regulatory requirements. Third, the resulting structure is engineered and embodied into an industrially feasible layout. (4) Conclusions: The method is able to develop an original, brand new tower-like pylon integrating all the types of requirements, such as regulatory, industrial feasibility, and social components' needs. The resulting electricity pylon presents an enhanced visual quality according to the citizens' feedback.
\end{abstract}

Keywords: integrated design method; electricity pylon; visual impact improvement; topology optimization 


\section{Introduction and Related Works}

High-voltage power lines (HVPLs) are artificial structures with many controversial effects. On the one hand, they are facilities that enhance human activity by responding to the increasing demand for power supply and capillary distribution as well as serving the widespread development of renewable energy sources. On the other hand, they are huge and massive human artefacts with many potential consequences on people's health and safety, but also affecting the natural landscape. Leaving out health considerations, the scope of this research activity is focused on the visual impact of these facilities on the landscape, with consequences for society, tourism, and ecology.

HVPLs mainly consist of tall tower-like pylons, which are generally lattice structures supporting conductors, guard ropes, and hood and pin insulators. However, the element having the greatest visual impact for HVPLs is the pylon, with a disrupting effect on the aesthetics and the perception of natural and rural landscapes. In all the published papers in the related literature [1-4], the burying of cables is found to offer the best mitigation of the visual impact of the HVPLs: this solution produces social benefits and a lack of visual impact on the landscape but presents some limitations. The first one is the high real cost associated with burying lines. Navrud et al. [5] quantified that in Norway the costs of underground cables of higher voltage lines are up to 8-10 times greater than the costs of overhead lines; it is difficult for municipalities to bear an additional cost compared to overhead lines. The second limitation on buried power lines is the presence of landscape/environmental constraints and natural barriers, as in the case of natural reserves, rivers, valleys, mountains, and so on, which do not allow the installation of this kind of solution.

Therefore, in the majority of cases, overhead power lines are still the most frequently used solutions, with the main drawback being their visual impact. This has originated multiple attempts of solutions from governments and organizations in most countries.

The first trend is the development of studies and guidelines provided by national institutions (e.g., [6-8]) for the mitigation of the visual impact of infrastructures. These sources consider all the development phases (siting, design, production, installation, decommissioning). In accordance to the scope of this work, the most important guidelines regard the structure design. Reed [7] recommends the use of custom-designed structures in key areas when such designs would soften the visual impact and blend more effectively with the surroundings, as well as of different kinds of structures (monopole, guyed, and lattice structures/towers) to be used with regard to the given landscape setting. The Environmental Protection Department [8] highlights how the visual impact varies in consideration of the degree of change to the baseline conditions. With particular respect to electric pylons, Koglin and Gross [1] provide two main statements:

- The design of high voltage pylons is particularly critical since they are visible from a long distance.

- The visual impact depends on the landscape, the pylon position, the angle of the observer, and the contrast.

Similarly, Sumper et al. [3] propose a measure of the visual impact of different pylons in the same situation as the multiplication of three terms: the visibility of the facilities, the fragility of the landscape (which increase or decrease the impact), the nature of the area (industrial, commercial, rural, etc.).

Again, Reed [7] suggests that the selection of materials and surface treatments should repeat the form, line, color, and texture of the surrounding landscape.

However, since the visual impact is a subjective perception, most of the guidelines provide advice and/or requirements about the assessment of the potential visual impact that the designer is required to consider but they still depend on the designer's subjectivity.

Since the same subjectivity lies in the citizen, the second trend of potential mitigation actions comes from the direct involvement of citizens through participatory workshops and consultation as well as design contests in the case of new installations. The use of deliberative focus group methods leads to an exploration of the citizens' perceptions of environmental and social impacts, risks, governance arrangements, and technology choices [4]. Again, the citizens' involvement in the decision making 
process from an early stage of design can be considered as a mitigation measure that would lead to greater levels of acceptability, taking into account the characteristics, concerns, needs and expectations of the specific communities to be affected [9].

Similarly, design contests enhance the psychological perception of direct participation in the design process. In addition, they aim to identify new ideas by crowdsourcing, even if the design solutions are usually stopped at the conceptual phase [10] and not further developed into real structures. The main reason is the citizens' lack of technical knowledge necessary to take a strategic viewpoint on transmission system development [4], as well as similar limitations in the fields of regulatory, safety, lack of feasibility, etc.

However, a few solutions coming from the design contests are developed into real structures and put in place in some European countries. In this case, actually, the citizens only judged and selected the best design among the works proposed by professionals and architectural firms. The winning designs present attractive and sinuous shapes, different from the traditional ones. The preferences for these alternative pylon designs are studied in [9]: this study compares the "T-pylon" [11], designed by the Danish architect Erik Bystrup and put in place in 2015 in the UK (Figure 1a) with two other different designs. One of the main results of the survey highlights that traditional pylon design is, typically, perceived as having a negative visual impact, "which probably stems from its historical associations as being big or huge, monstrous, ugly and as eyesores" [9].

Similarly, a direct comparison between the conventional lattice structure and new pylon designs (single pole with arms, one pole, double pole with arms, V-pole, windmill, etc.) is proposed in [2,12]. The preferences of people for alternative pylon designs is mainly correlated to their negative perception of the conventional structure (reticular structure or truss), generally associated with the impact of the infrastructure. In particular, new pylons designs were developed and compared to the existing ones (i.e., lattice structures) by carrying out a survey among residents in the area of installation [2]. After asking about their preferences about the pylon designs, survey respondents were asked if they would pay for changing the existing pylons with their preferred one. The results of this study were also reanalyzed in [13], highlighting that (1) the majority of respondents had no intentions to pay for a new pylon design and, moreover, (2) they thought there was no difference between maintaining and replacing the current design. However, other examples of already installed real pylons with alternative designs are the "Rosental pylon", designed by Hugh Dutton Associés and architect Giorgio Rosental and put in place in 2014 in Italy (Figure 1b), and the "Foster pylon" [14] designed by architect Sir Norman Foster (Foster+Partners) and put in place in 2009 in Italy (Figure 1c).

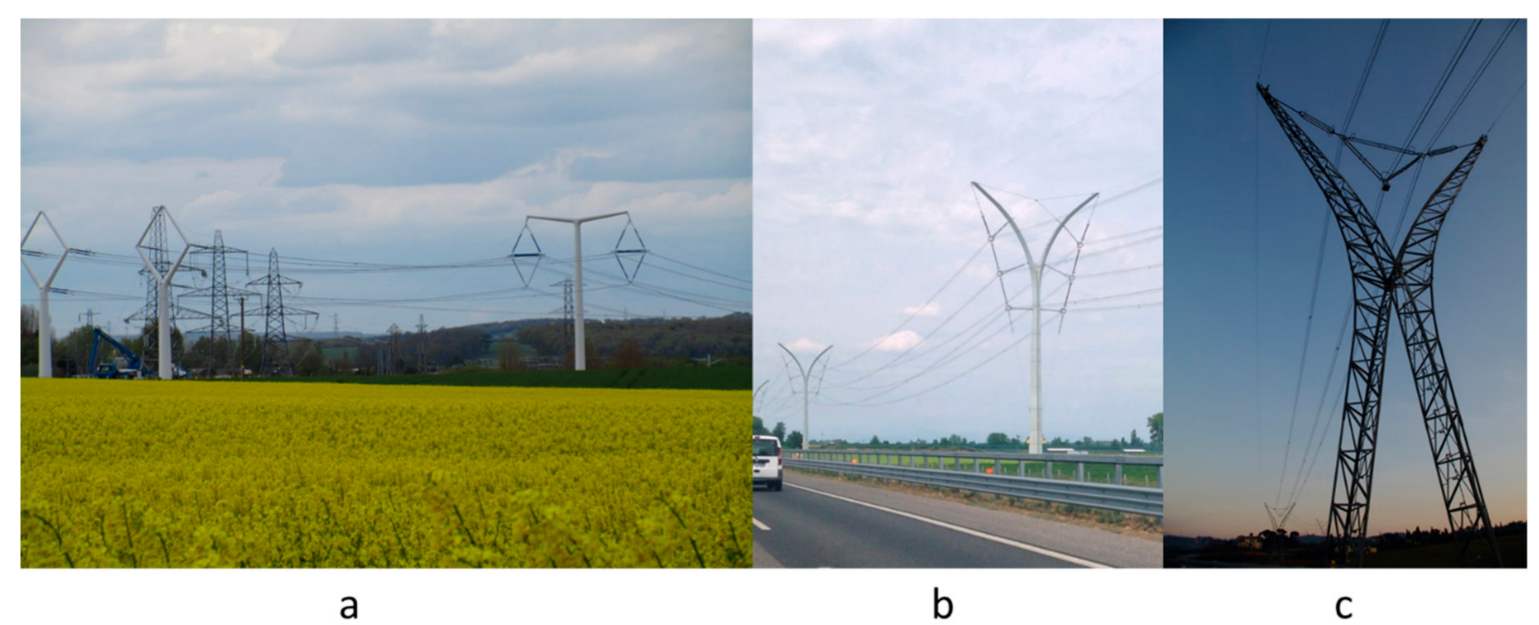

Figure 1. Examples of already installed pylons with alternative designs: (a) T-pylon, installed in the UK [15]; (b) Rosental pylon, installed in Italy by Italian energy company Terna SpA [16]; (c) Foster pylon, installed in Italy by Terna SpA (Photo credits: Terna SpA) [17]. 
All these new types of installed pylons (Figure 1) aim to enhance the visual impact quality, even if they do not completely adopt the suggested design guidelines. In particular, they do not have characteristic elements that are easily associated with the surrounding landscape in which they are installed, which could better integrate them with the landscape, further improving their quality impact.

A further consideration comes from the Countryside Agency and Scottish Natural Heritage [13], which provides the following definition of landscape:

"Landscape [... ] results from the way that different components of our environment-both natural (the influences of geology, soils, climate, flora and fauna) and cultural (the historical and current impact of land use, settlement, enclosure and other human interventions). People's perceptions turn land into the concept of landscape. This is not just about visual perception, or how we see the land, but also how we hear, smell and feel our surroundings, and the feelings, memories or associations that they evoke."

From the previous statement, we can achieve two key-factors involved in the definition of landscape:

- The "cultural" elements of a land/territory as landscape main factors, in addition to natural elements.

- The "perceptions" of the landscape as a mix of sight as well as feelings (i.e., physical as well as psychological sensations).

Therefore, the visual impact is also related to people's visual amenity, which is defined as: "the overall pleasantness of the views they enjoy of their surroundings" in Guidelines for Landscape and Visual Impact Assessment-Third Edition, 2013 (GLVIA3) [18].

Again, the GLVIA3 [18] states:

"An assessment of visual effects deals with the effects of change on views available to people and their visual amenity. The concern here is with assessing how the surroundings of individuals or groups of people may be specifically affected by changes in the content and character of views as a result of the change or loss of existing elements of the landscape and/or introduction of new elements."

Within the mitigation measures to be implemented in the design of facilities, [19] includes the following requirement/guideline among the others:

"Where it is not practicable to screen or integrate a facility into the landscape, consider designing the facility to be a feature in the landscape, taking into consideration the form, texture and arrangement of buildings and structures."

To sum up, the related literature review highlights the lack of recent methodological innovation capable of supporting the development of alternative design of pylons, with an enhanced visual quality. The current design method is based on the optimization of reticular structures (or trusses) made of galvanized steel [20-24], focusing on the reduction of the cost of material, transportation, erection, and maintenance. An interesting approach to topology in the pylon design is presented in [25]. With respect to the visual impact, all these approaches completely neglect the integration of the design process with methods for enhancing its quality, and the shape of pylons placed in very different areas does not present structural nor morphological differences between urban, agricultural or wild areas.

Again, the literature review highlights two opposite point of views about visual impact. On the one hand, according to Reed [7], the visual impact may be defined as "any modification in landforms, water bodies, or vegetation, or any introduction of structures or other human-made visual elements, that negatively or positively affects the visual character or quality of a landscape through the introduction of visual contrasts in the basic elements of form, line, color, and texture". On the other hand, the visual impact, depending on the subjective perception of the observer, could be improved thanks to 
harmonious elements with respect to the landscape, but also which bring to people's mind cultural, historical, naturalistic references, suggesting harmonious and not disruptive perceptions.

This paper presents a systematic method for the morphological design of electricity pylons and their Topology Optimization (TO), which takes into account all the sources of requirements, such as regulatory, industrial feasibility, and social components, as measures to improve the visual impact quality, including landscape, cultural, and environmental symbolism. In particular, the paper focuses on the identification and integration of multidisciplinary references, such as cultural, traditional, historical, natural, etc., in the design process of a human artefact, such as an electricity pylon. By creating symbolic perceptions in people/citizens, the new pylon design aims to enhance the acceptance of landscape changes as well as softening the visual disamenity caused by the artefact.

The paper is structured in four sections. In the first section, we introduce the proposed method with a synthetic list of the main steps. In the second section, we apply the method to the design of electricity pylons for an Italian region that presents multiple geographical and cultural references. In the third section, we discuss the results of the method and finally, in the last one, we present the conclusions and future steps.

\section{Method}

In this section, we propose a method capable of developing new pylon designs that, besides functional and regulatory, focuses also on people's visual perceptions of these human artefacts. Specifically, if we could divide a certain geographical landscape into various areas such that each of them can be represented by a certain geometry or shape, the pylon design could recall the representative shape of that area. With respect to the proposed literature review, this method can add a potential missing piece in the wider field of the design for improving the visual impact mitigation. Therefore, in this section we define a method to systematically support the designer of pylons (or similar tower-like structures) through an original design strategy based on the following steps:

1. Identification of requirements due to safety conditions imposed by the relevant legislation, safety, enhancing of the visual quality, and analysis of citizens' needs.

2. Definition of a landscape subdivision criterion and identification of symbols or shapes that highly represent the areas where the pylons will be placed. Different criteria may be identified, but the most relevant are geographical elements, natural elements (such as the vegetation) or, more generally, items of interest (such as symbolic shapes for the location). Each criterion requires firstly to divide the region into areas and, then, to identify symbols or shapes capable to be representative as well as consistent with each area. This operation requires a deep knowledge of the territory, from different point of views (history, local culture, geography, nature, etc.), which can be achieved by the involvement of a multidisciplinary team as well as citizens from the region. After a first brainstorming collection phase of symbol and shape proposals, in the case of more than one candidate for each area, the designer needs to select only one symbol/shape. An approach based on the elicitation of the citizens' preferences in accordance with [26] can be proposed.

3. Development of conceptual solutions for the new pylon, starting from a representative shape of the installation site, but considering all the functional requirements of electricity transmission and distribution lines. The main substep is the 3D modelling of the starting shape (input for the TO), which can be achieved by means of direct Computer-Aided Design (CAD) modelling, reverse modelling or their integration [27-31].

4. TO of each promising shape to define a geometry that is structurally efficient and respectful of the constraints imposed by the requirements. The main substeps are:

- $\quad$ The definition of the design space.

- $\quad$ The definition of load conditions. 
- The first weight reduction and the analysis of results.

- $\quad$ The final weight reduction and the analysis of results.

- $\quad$ The structure embodiment into a feasible layout.

The last two substeps mean materials and weight reduction starting from the early design phases [32-34] but represents also the chance for the designer to improve the design quality [35].

5. Definition of a feasible layout and its final embodiment into a real structure in order to obtain an industrial product that can be implemented and installed but that still retains the characteristic traits of the original form.

6. Assessment of the final design of the pylon: a survey among citizens of the region where the pylons will be placed may be carried out with the support of renders, scenario, etc. (as in [26]).

The method follows the workflow shown in Figure 2 and is structured in accordance with the main phases of the systematic design approach [36].

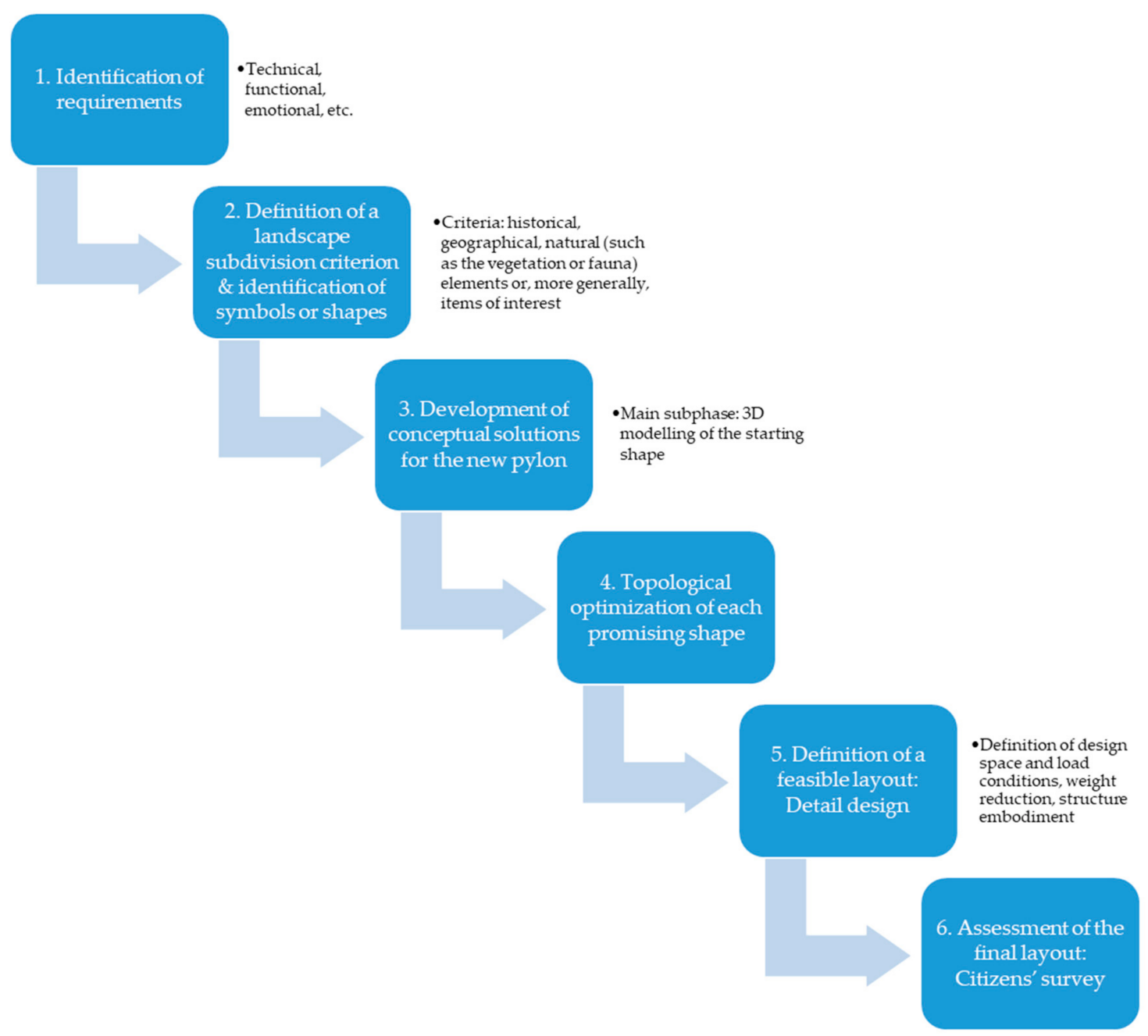

Figure 2. Flow-chart of the proposed method.

In this way, the systematic design method advantageously exploits the inevitable impact of pylons on the landscape while maintaining all the functional requirements in the distribution of electricity energy. 


\section{Method Implementation and Application}

This section presents the method application and its results with respect to the selected case study, which is the development of an electricity pylon for the Abruzzo region, in Italy. We selected this region because it presents different landscape areas, such as the coastal area, the mountains area with very high peaks, and natural reserves, but also important cultural and historical cities; so, the problem of the visual impact of artificial structures on these landscapes is highly relevant. This landscape variety, as well as this cultural and traditional richness, are common to many other European regions and worldwide countries, to which the method can be further applied.

In the following subsections, we describe how to apply the proposed method to this territory and present the developed outcomes. Our main goal is the development of a structure with an improved visual quality respect to the state-of-the-art, but fully respecting all the requirements, such as regulatory, safety, industrial feasibility, and social components' needs.

The suspension pylons of power lines may be developed in an advantageous way, making them an element of enrichment of the landscape itself. This is the idea underlying all the pylons previously called "aesthetic". However, in the proposed method, we want to take a further step by designing the pylon as an identification element of the landscape where it will be placed.

The case study addresses the design of a new electricity pylon for a $380-\mathrm{kV}$ line to be installed in the Abruzzo territory. However, it should be noted that its application to a specific case does not limit its generality; indeed, it is easily extendible to global landscapes for which it is possible to identify characteristic shapes.

\subsection{Electricity Pylon Requirements}

We need to identify the requirements due to safety conditions imposed by the relevant legislation, improvement of the visual impact quality, and analysis of customers' needs.

First, concerning standards and rules, we have two references: The International Electro-Technical Commission (IEC), as well as the related continental and national standards and legislation, that the pylon design has to comply with. These kinds of requirements are mandatory, with higher priority. With regard to the standard context and referring to the Italian Ministerial Decree 21/03/1988 n.449, the proposed case study deals with a third-class line (referred to as HHT, with a nominal voltage higher than 30,000 V). The corresponding requirements are listed in the first column of Table 1 in rows 1-17.

Second, the new structures should be designed by considering the visual impact. In accordance with this aim, some specific requirements could be identified with regard to the impact (e.g., in areas of high landscape interest, in protected areas), integration in urban contexts, and global aspects (e.g., as identifiable with the power supply field). The corresponding requirements are listed in the first column of Table 1 in rows 18 and 19.

Additional requirements may come from the citizens' needs. In accordance with [26], citizens can be considered as "non-technical customers", based on the way in which they perceive and communicate their needs. The citizens' needs, such as implicit or emotional needs, have to be identified, analyzed, and translated into technical specifications. In our case study about electricity pylons, most of the technical requirements are integrated with the standard/legal ones (compare rows 1-17 of the second column of Table 1), while the non-technical ones consider the landscape or the visual impact (compare rows 18 and 19 of the second column of Table 1).

The second column of Table 1 presents the functional requirements in accordance with the functional analysis of the pylon. The third and fourth columns present the units and the quantity (e.g., the numerical target value) associated to the related functions. The last column lists the priority score that the designer has assigned to each requirement. To this aim, a five-point Likert-type scale was used, from 1 (no priority) to 5 (high priority).

Finally, all the requirements were translated and integrated into functions able to describe the performance of the pylon. To each function, a score was assigned by transferring the assessed scores to the corresponding technical requirements. 
Table 1. Technical specifications for a pylon of a 380-kV electricity line.

\begin{tabular}{|c|c|c|c|c|c|}
\hline No. & Functional Requirements & Units & $\begin{array}{c}\text { Functional } \\
\text { Requirement }\end{array}$ & Note & Priority \\
\hline 1 & $\begin{array}{l}\text { Number of lines that can be } \\
\text { supported by the pylon }\end{array}$ & (lines) & $\mathrm{FR}>1$ & With modularity: 3-6 & 5 \\
\hline 2 & $\begin{array}{l}\text { Accessibility for maintenance } \\
\text { operations }\end{array}$ & (unitless) & Largest possible & Usually 1 day & 4 \\
\hline 3 & $\begin{array}{c}\text { Frequency of maintenance } \\
\text { operations }\end{array}$ & (n/year) & Smallest possible & $\begin{array}{l}\text { Usually one } \\
\text { operation/year }\end{array}$ & 4 \\
\hline 4 & Unit installation cost & $(€)$ & $<750 \mathrm{k€} / \mathrm{km}$ & $\begin{array}{l}\text { Reference value for the } \\
\text { most important operator } \\
\text { of energy transmission }\end{array}$ & 4 \\
\hline 5 & Unit installation time & (day) & (days) & $\begin{array}{l}\text { Usually between } 1 \text { and } \\
10 \text { days }\end{array}$ & 4 \\
\hline 6 & Support height & $(\mathrm{m})$ & $35 \leq \mathrm{FR} \leq 45$ & $\begin{array}{l}\text { Even higher in particular } \\
\text { cases }\end{array}$ & 4 \\
\hline 7 & $\begin{array}{l}\text { Adaptability of mechanical } \\
\text { properties to specific applications }\end{array}$ & (unitless) & Yes & & 4 \\
\hline 8 & $\begin{array}{l}\text { Values range of area of the } \\
\text { support base }\end{array}$ & $\left(\mathrm{m}^{2}\right)$ & $10 \leq \mathrm{FR} \leq 16$ & $\begin{array}{l}\text { Smallest area to reduce } \\
\text { impact }\end{array}$ & 4 \\
\hline 9 & $\begin{array}{l}\text { Adaptability of foundations to } \\
\text { any soil medium }\end{array}$ & (unitless) & Yes & & 4 \\
\hline 10 & $\begin{array}{l}\text { Adaptability to both natural and } \\
\text { urban contexts }\end{array}$ & (unitless) & Yes & & 4 \\
\hline 11 & $\begin{array}{l}\text { Compliance with mechanical } \\
\text { properties imposed by standards }\end{array}$ & (unitless) & Yes & & 5 \\
\hline 12 & $\begin{array}{l}\text { Distance between the conductors } \\
\text { and the ground }\end{array}$ & (m) & $\mathrm{FR} \geq 11.3$ & & 5 \\
\hline 13 & Distance between conductors & $(\mathrm{m})$ & $\mathrm{FR} \geq 5$ & & 5 \\
\hline 14 & $\begin{array}{l}\text { Distance between conductors and } \\
\text { ground parts of the support }\end{array}$ & $(\mathrm{m})$ & $\mathrm{FR} \geq 2.3$ & & 5 \\
\hline 15 & Vulnerability to lightning & (unitless) & No & & 5 \\
\hline 16 & Short circuit safety & (unitless) & Yes & & 5 \\
\hline 17 & $\begin{array}{l}\text { Vulnerability in extreme weather } \\
\text { conditions }\end{array}$ & (unitless) & No & & 3 \\
\hline 18 & Ease of disposal & (unitless) & Appreciated & & 3 \\
\hline 19 & $\begin{array}{l}\text { Visual impact mitigation } \\
\text { strategies }\end{array}$ & (unitless) & Largest possible & & 5 \\
\hline
\end{tabular}

\subsection{Definition of a Landscape Subdivision Criterion and Identification of Symbols or Shapes}

The geographical area of reference for the application of the method is the Abruzzo region, selected as a case study. The proposed method requires dividing the region area into various subareas, each of them represented by a specific geometry or, better, a representative shape of that area. The first step concerns the definition of a criterion for dividing the geographical areas into places represented by some shape.

The definition of a landscape subdivision criterion must meet the following requirements:

1. The number of areas identified must not be too large, otherwise too many types of supports should be defined, and this would have obvious complications.

2. The representative shapes must be adequate for the purpose: the pylon slenderness is a key feature for a technical solution to be implemented even on a large scale.

3. The areas must be sufficiently identifiable with the chosen representative shapes.

In the following subparagraphs, a list of suggested criteria for landscape subdivision is proposed, whose resulting symbols are summed up and listed in Table 2. 
Table 2. Criteria for the subdivision in areas.

\begin{tabular}{|c|c|c|c|c|c|}
\hline \multirow[b]{2}{*}{ Criterion } & \multicolumn{3}{|c|}{ Description } & \multicolumn{2}{|c|}{ Judgements } \\
\hline & Area & $\#$ & Symbol & $\begin{array}{l}\text { Renowned } \\
\text { Shape }\end{array}$ & $\begin{array}{l}\text { Shape/Area } \\
\text { Consistency }\end{array}$ \\
\hline \multirow{11}{*}{ History } & Marsica & A1 & Goddess Angizia statue & 7 & 8 \\
\hline & Provincia Chieti & A2 & Achille statue & 10 & 8 \\
\hline & Pescara Popoli & A3 & Capestrano Warrior statue & 9 & 10 \\
\hline & Teramo Atri & A4 & Roman statue & 7 & 7 \\
\hline & Amiterno & A5 & Dominus Amiterno statue & 7 & 7 \\
\hline & Alba Fucens & A6 & God Ercole statue & 9 & 7 \\
\hline & Peligna-Corfinium & A7 & Ovidio statue & 9 & 8 \\
\hline & L'Aquila & A8 & Medieval emblem on shield & 7 & 7 \\
\hline & Peligna-Scanno & A9 & Medieval emblem on shield & 6 & 6 \\
\hline & Avezzano e Valle del Liri & A10 & Torlonia monument & 6 & 6 \\
\hline & Pescara & A11 & Fishing boat & 8 & 7 \\
\hline \multirow{4}{*}{ Province } & L'Aquila province & B1 & Province emblem & 9 & 9 \\
\hline & Teramo province & B2 & Province emblem & 5 & 5 \\
\hline & Chieti province & B3 & Province emblem & 7 & 6 \\
\hline & Pescara province & B4 & Province emblem & 7 & 6 \\
\hline \multirow{3}{*}{ Geography } & Mountains & $\mathrm{C} 1$ & Hiker & 8 & 8 \\
\hline & Hills & $\mathrm{C} 2$ & Grape bunch & 8 & 6 \\
\hline & Coasts & C3 & Sail boat & 9 & 9 \\
\hline \multirow{3}{*}{ Vegetation } & Rdp1 & D1 & Oak tree & 7 & 6 \\
\hline & Rdp2 & D2 & Beech tree & 7 & 6 \\
\hline & Rdp3 & D3 & Beech tree & 7 & 7 \\
\hline \multirow{4}{*}{ Fauna } & $\begin{array}{l}\text { Abruzzo Lazio and Molise } \\
\text { National park }\end{array}$ & E1 & Sitting bear & 9 & 9 \\
\hline & Gran Sasso and Monti della & E2 & Chamois & 9 & 8 \\
\hline & Majella National park & E3 & Wolf & 9 & 8 \\
\hline & Velino-Sirente Regional park & E4 & Eagle & 9 & 7 \\
\hline
\end{tabular}

According to the results reported in [24], a better correspondence between the identified shapes and the citizens' requirements can be obtained by involving local residents in participatory design activities [37-39]. A survey was conducted among 120 people between the ages of 18 and 65, divided into 54 men and 66 women, from different social backgrounds who live in the Abruzzo region and equally distributed throughout the whole territory. For each of the identified criteria (see the following subparagraphs), each person was asked to assign a score to each proposed shape to assess its renown (assigning a score of 1-10) and the consistency of the symbol (assigning a score of 1-10) with the specific area. All the judgements are collected in the last two columns of Table 2. The average of these scores determined the "shape suitability" scores in the following Tables (from 3 to 8 ) for each subdivision criterion.

\subsubsection{Subdivision by Historical Aspects}

Since there was no political center, the numerous cities of Abruzzo, each of ancient origins and brilliant civilization, followed their own history independently:

- The origin of Touta Marouca (later called Teate and then Chieti) is lost in the mists of time.

- Marruvium and Corfinium were pre-Roman centers.

- Atri, Alba Fucens, and Amiternum flourished under the Roman Empire.

- Sulmona and L'Aquila flourished in the Middle Ages.

Pescara and Avezzano developed in an increasingly important way from the end of the 19th century.

The symbolism requires truly identifying the areas, therefore, each city was represented by a symbol belonging to the period in which it was most flourishing, both economically and socially (Figure 3). 


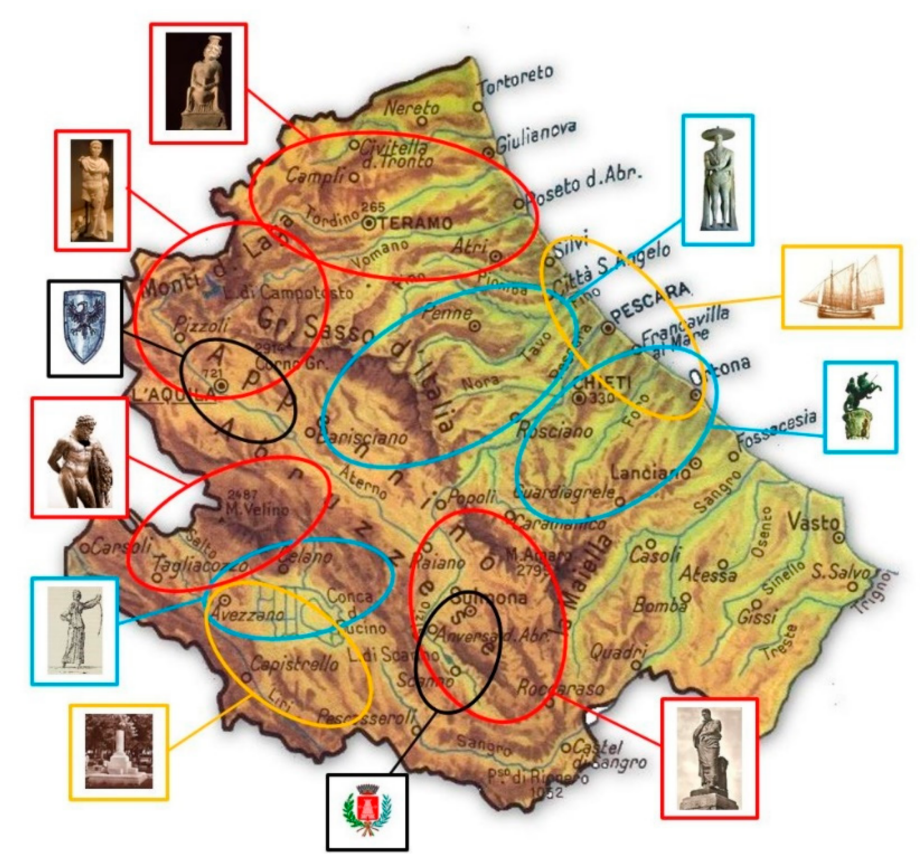

Figure 3. Subdivision by historical aspects.

The criterion produced 11 symbols (see Table 2). Table 3 shows the performance of the criterion, which is unsuitable as it does not fully respond to all the requirements.

Table 3. Assessment of the criterion: subdivision by historical aspects.

\begin{tabular}{ccc}
\hline Requirement & Score & Judgement \\
\hline Number of identified areas & 11 & Too high \\
Shape suitability & Medium-high & Adequate \\
Shape/area consistency & 7.5 & Generally adequate but in some cases not sufficient \\
\hline
\end{tabular}

\subsubsection{Subdivision by Provinces}

Each of the Italian Region is divided into provinces, as shown in Figure 4, each having an emblem or flag.

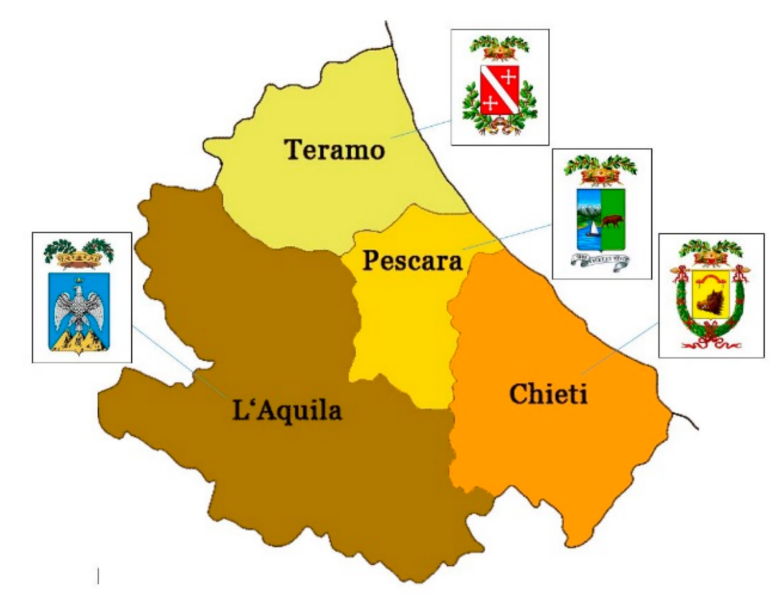

Figure 4. Subdivision by provinces.

The criterion produced four symbols (see Table 2). Again, the criterion results are unsuitable, as they do not fully respond to all the requirements (Table 4). 
Table 4. Assessment of the criterion: subdivision by provinces.

\begin{tabular}{ccc}
\hline Requirement & Score & Judgement \\
\hline Number of identified areas & 4 & Adequate \\
Shape suitability & Low & Not adequate \\
Shape/area consistency & 6.8 & Generally not adequate except for L'Aquila \\
\hline
\end{tabular}

\subsubsection{Subdivision by Geographical Elements}

Abruzzo has very different characteristics determined by the presence of numerous mountain valleys to the west and internal basins, but it also has a coastal strip on the eastern side. The three geographical elements could be used as elements to identify the local representative shapes:

- Mountains.

- Hills.

- Coasts.

Each geographical area could be represented by a representative symbol, as shown in Figure 5 (see also Table 2).
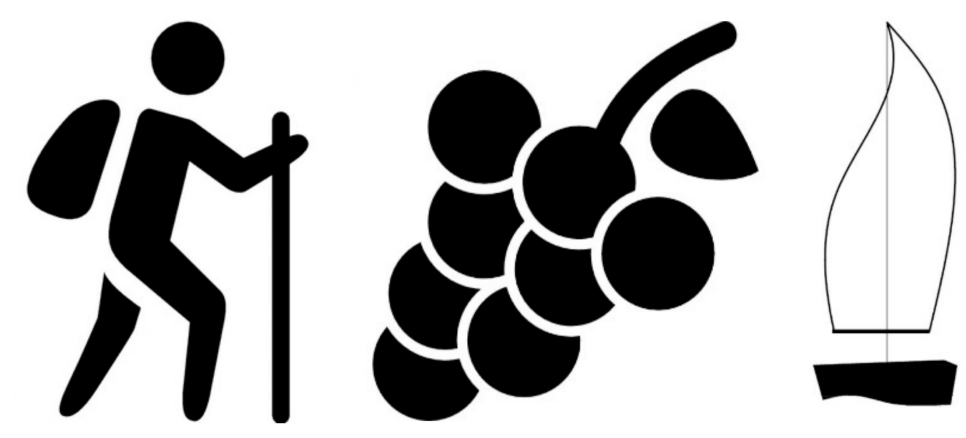

Figure 5. Subdivision by geographical elements.

As usual, we proceeded with the analysis of the criterion, which does not fully respond to all the requirements (Table 5).

Table 5. Assessment of the criterion: subdivision by geographical elements.

\begin{tabular}{ccc}
\hline Requirement & Score & Judgement \\
\hline Number of identified areas & 3 & Adequate \\
Shape suitability & Medium-Low & Only partially adequate \\
Shape/area consistency & 7.7 & Generally adequate except for the grasp bunch \\
\hline
\end{tabular}

\subsubsection{Subdivision by Vegetation}

The predominant natural element of Abruzzo region is made up of the numerous centuries-old woods scattered throughout the region. For this reason, we considered the tree distribution as a potential landscape subdivision factor. In this sense, three main areas can be identified:

- The Adriatic coast of Abruzzo (Region-of-Origin 1 (RoO1) 1 in Figure 6), which extends from north to south along the entire coast and is bordered to the west by the slopes of Majella and Gran Sasso d'Italia. This first area includes woods with a prevalence of Mediterranean plants such as oak trees.

- The second area (RoO2 in Figure 6, divided into three subzones 2a, 2b, 2c) includes the coastal strip at higher altitudes (east sides of Gran Sasso and Majella) and insinuates itself into the center of the region including the Fucino plain and the Aquila hinterland. This area is characterized mainly by beech trees. 
- The third area (RoO3 in Figure 6) is the most fragmented geographically and includes the major mountain ranges of the Region (Gran Sasso, Majella, Sirente-Velino, Marsicano Mountains). Again, the beech woods are the forest populations that extend most: they cover more than $50 \%$ of the total area.

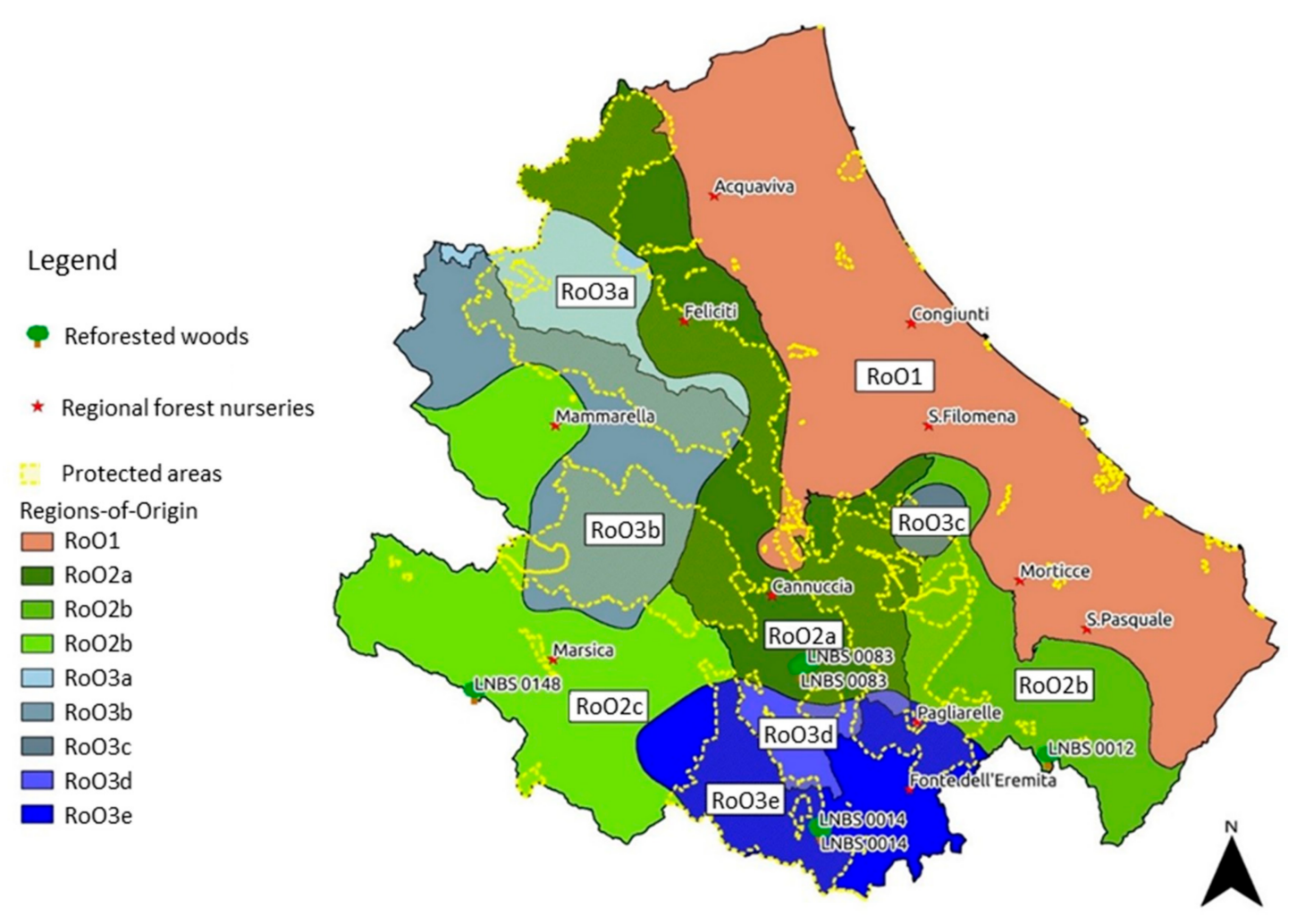

Figure 6. Subdivision by vegetation.

The criterion produced three symbols (see Table 2). Again, the criterion results are unsuitable, as they do not fully respond to all the requirements (Table 6).

Table 6. Assessment of the criterion: subdivision by vegetation.

\begin{tabular}{ccc}
\hline Requirement & Score & Judgement \\
\hline Number of identified areas & 3 & Adequate \\
Shape suitability & Medium-Low & Only partially adequate \\
Shape/area consistency & 6.3 & Not adequate except for the Rdp3 case area \\
\hline
\end{tabular}

\subsubsection{Subdivision by Fauna}

A similar division can be performed starting from the National and Regional protected areas (Figure 7) and from the animals that reside there:

- National parks: Abruzzo, Lazio and Molise National park; Gran Sasso and Monti della Laga National Park; Majella National park.

- Regional parks: Sirente-Velino natural regional park. 


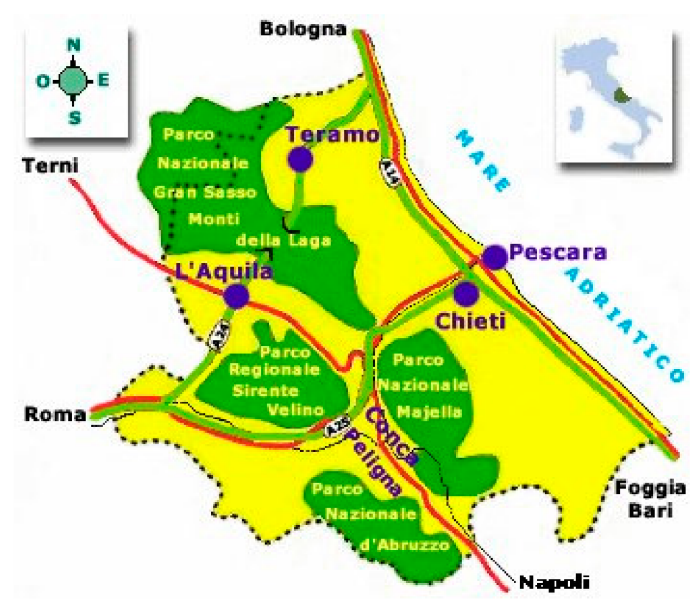

Figure 7. Subdivision by fauna.

The fauna resident in the various parks can be summarized in Table 2. The criterion produced four symbols. Again, the criterion results are unsuitable, as they do not fully respond to all the requirements (Table 7).

Table 7. Assessment of the criterion: subdivision by fauna.

\begin{tabular}{ccc}
\hline Requirement & Score & Judgement \\
\hline Number of identified areas & 4 & Adequate \\
Shape suitability & Medium-Low & Only partially adequate \\
Shape/area consistency & 8 & Adequate \\
\hline
\end{tabular}

\subsubsection{Subdivision by Items of Interest}

Since none of the previous criterion fully responded to the requirements, we defined a "combined" criterion: we proceeded without considering a univocal criterion on the whole region, but selecting the shapes that best met the various requirements among the symbols identified by the different criteria for each location.

Table 8 sums up the elements that best meet the previous criteria and the corresponding representative shapes. They are (Figure 8):

- The statue of the Capestrane Warrior for the province of Pescara Popoli.

- The emblem (coat of arms) of the province of L'Aquila, of medieval origin, is an eagle and coincides with the symbolic animal of the Velino-Sirente area and, by extension, of Marsica too.

- The sailing boat (or simply a sail) for the coastal area.

Table 8. Final criteria for the subdivision in areas (subdivision by items of interest).

\begin{tabular}{|c|c|c|c|c|c|}
\hline \multirow[b]{2}{*}{ Criterion } & \multicolumn{3}{|c|}{ Description } & \multicolumn{2}{|c|}{ Judgements } \\
\hline & Area & $\#$ & Symbol & $\begin{array}{l}\text { Renowned } \\
\text { Shape }\end{array}$ & $\begin{array}{l}\text { Shape/Area } \\
\text { Consistency }\end{array}$ \\
\hline History & Pescara Popoli & A3 & $\begin{array}{c}\text { Capestrano } \\
\text { Warrior statue }\end{array}$ & 9 & 10 \\
\hline Province & L'Aquila province & B1 & Province emblem & 9 & 9 \\
\hline Geography & Coasts & C3 & Sail & 9 & 9 \\
\hline Fauna & Velino-Sirente Regional park & E4 & Eagle & 9 & 7 \\
\hline
\end{tabular}




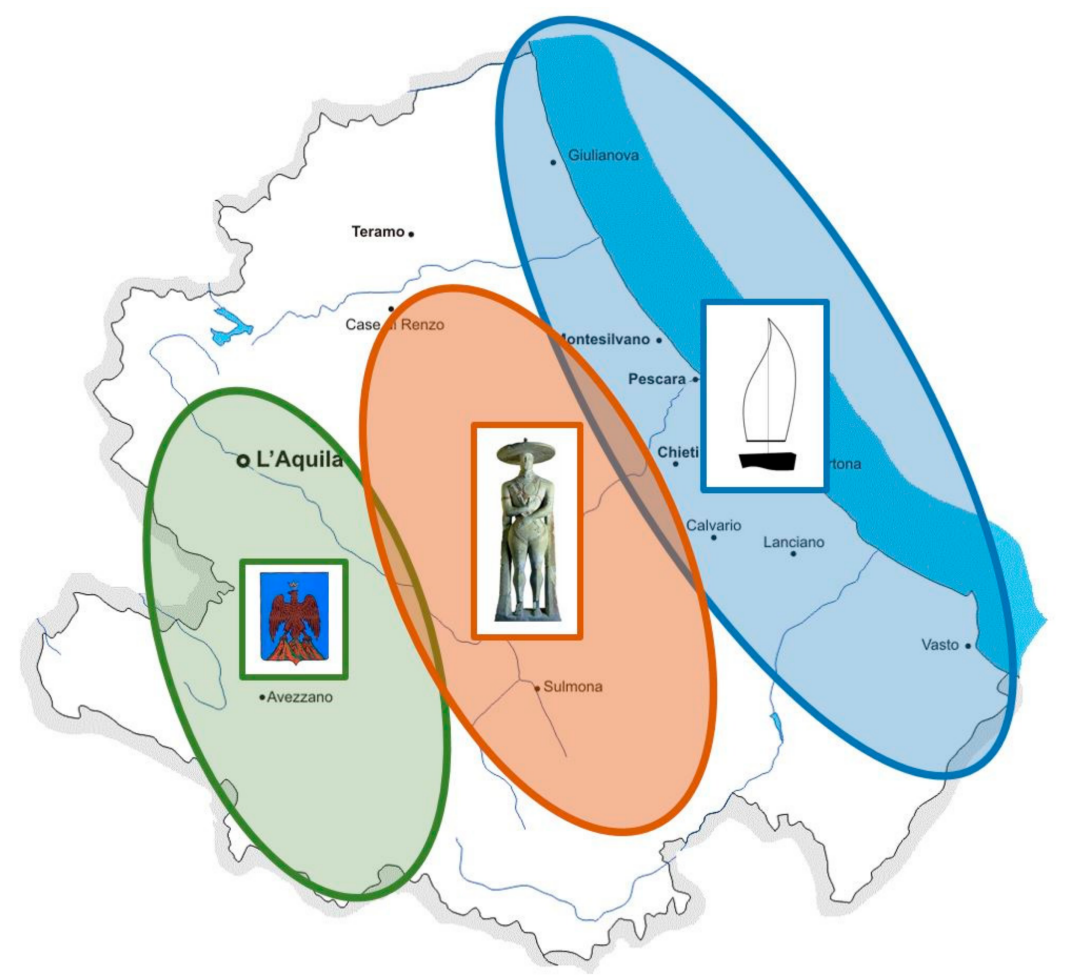

Figure 8. Subdivision by items of interest.

These were judged as symbols able to respond adequately to the judgement criteria (a representative form that is sufficiently famous and identified with the location) as well as suitable for use as the basis of new types of pylon (i.e., the shape is adequately streamlined).

To sum up, the multiple criteria proposed revealed a series of symbolic elements representative of certain areas, but the compliance with the requirements proved only partial in all cases. The final criterion, based on the most generic discriminating element possible, summarizes and identifies the most representative and performant shapes in accordance with the previous criteria.

\subsection{Development of Conceptual Solutions}

The subsequent step concerns development of digital models for each identified shape as inputs for the TO. The models can be achieved by means of direct CAD modelling, reverse modelling, or their integration. In the three-dimensional modelling phase, the virtual models of the proposed shapes have to be defined according to the following key features:

- Reproduction fidelity: the 3D models should present only the most representative details of the shape, avoiding marginal details that, in any case, will be lost in the subsequent TO.

- Scale factor: the 3D model has to be modelled according to the dimensions of the real pylon, since both the dimensional constraints and the load conditions defined by the standard for HHT power lines must be applied.

In other words, the development of conceptual solutions for the new pylon starts from a representative shape of the installation site, but considers all the functional requirements of electricity transmission and distribution lines. Figure 9 shows the 3D models for the 380-kV line pylons. Each model was studied and its correspondence to regulatory and standard constraints was assessed (Figure 10): we defined the positions of the anchoring points of the insulators that suspend the conductors of electric energy and guard ropes. This allows both a realistic definition of the loads and definition of the area in which the material must not be removed. Moreover, in the case of the sail-shaped model, which is the only one with a closed structure, we directly removed material 
from the sail by creating six holes sized accordingly to the regulatory constraints for the passage of the conductors.

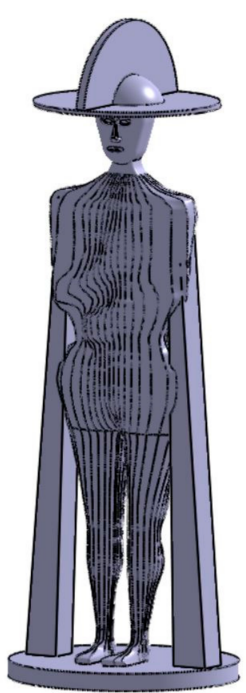

(a)

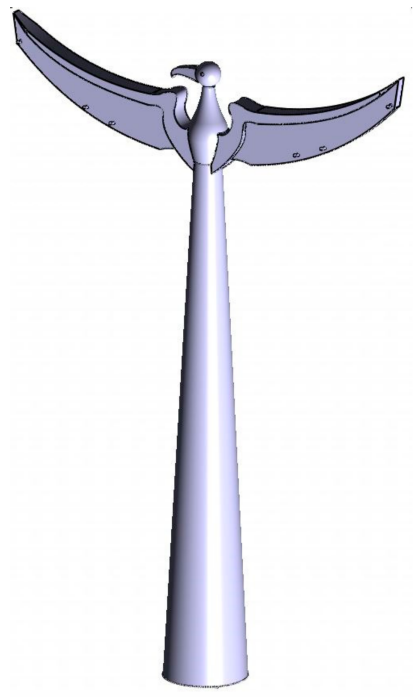

(b)

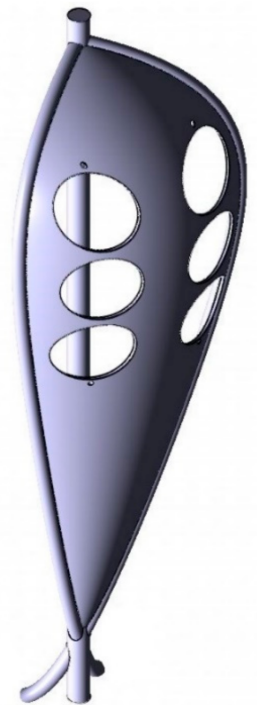

(c)

Figure 9. Starting 3D CAD models. (a) Capestrano Warrior statue; (b) Eagle; (c) Sail.

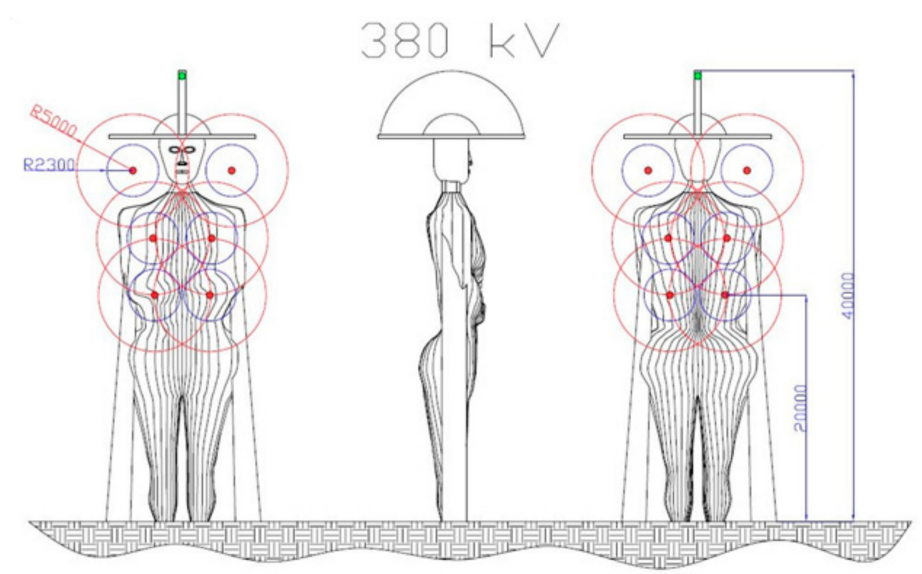

(a)

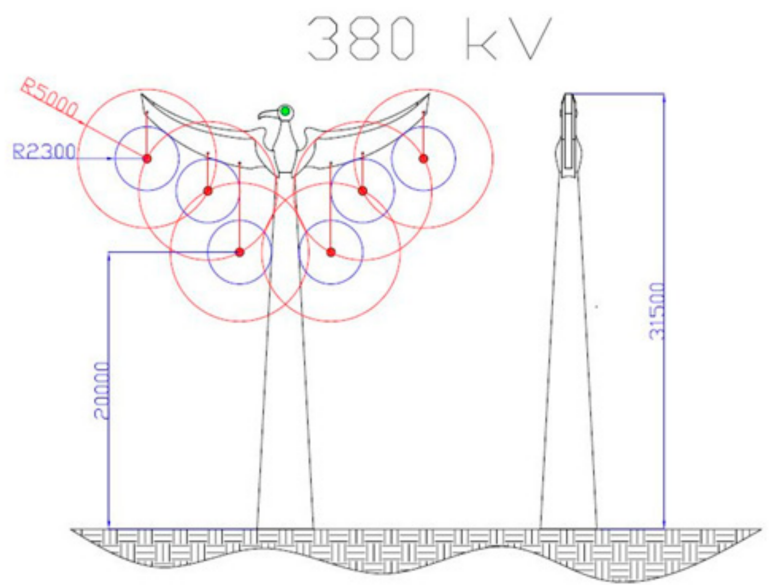

(b)

Figure 10. Cont. 


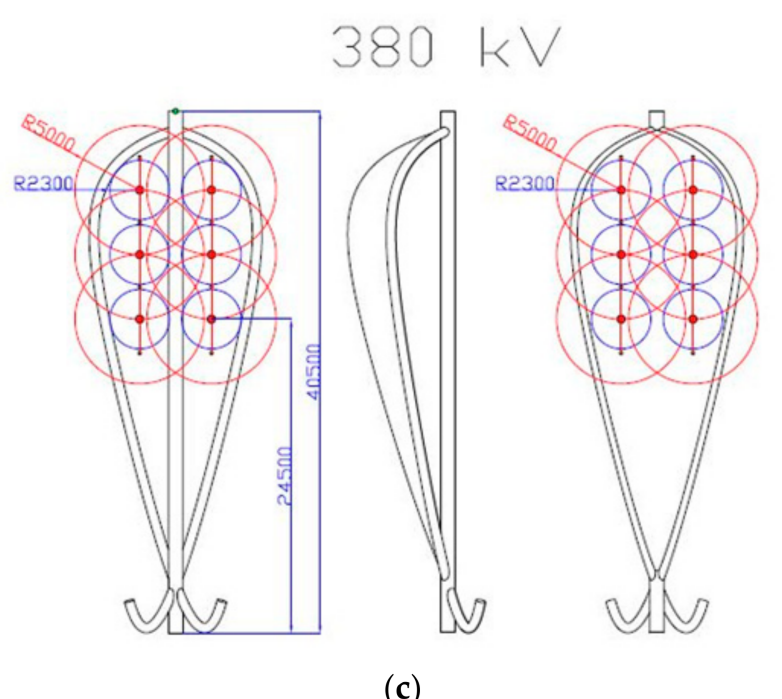

Figure 10. Preliminary set up of the 3D CAD model for the $380-\mathrm{kV}$ line. (a) Capestrano Warrior statue; (b) Eagle; (c) Sail.

The described steps and the resulting models started the conceptual design phase of the design process.

\subsection{Topology Optimization and Structural Analysis}

The next step is the TO of each promising shape to define a geometry that is structurally efficient and respectful of the constraints imposed by the requirements. The main substeps are:

- The definition of the design space.

- The definition of load conditions.

- The first weight reduction and the analysis of results.

- The final weight reduction and the analysis of results.

- The structure embodiment into a feasible layout.

The expected results are efficient structural models that have to resemble the starting shapes and respect the regulatory requirements. This phase corresponds to the embodiment design. Before performing a TO of the 3D CAD models of the representative shapes, we had to define the material, constraints, and loads as in the following list:

- Material: SAE 304 stainless steel, which is the most common stainless steel used in analyzed applications.

- Constraints: applied to the supports at the base of the pylon, which are fixed.

- Loads: see the reference standard, integrated in the law 1341/1964 and D.P.R. 1062/1968.

In particular, the pylons need to be verified in the following four Load Conditions (LC):

1. LC\#1: All conductors and guard ropes have to be intact at $-5^{\circ} \mathrm{C}$, with the wind blowing at 130 $\mathrm{km} / \mathrm{h}$ perpendicular to the electricity line.

2. LC\#2: Under the conditions of temperature and load of LC \#1, for the structures considered here, one conductor or one guard string is broken.

3. LC\#3: All conductors and guard ropes are intact at $-20{ }^{\circ} \mathrm{C}$ and under load due to the presence of ice sleeves on conductors or guard ropes, with the wind blowing at $65 \mathrm{~km} / \mathrm{h}$ perpendicular to the line.

4. LC\#4: Under the conditions of temperature and load of LC \#3, one conductor or one guard string is broken. 
According to the related standard and legislative specifications, the LC on the pylon are calculated by considering the following assumptions:

- The weight of the equipment is evaluated considering the chain of insulators, the terminal tower clamps, and any additional clamps.

- The wind thrust on the equipment is assumed to be equal to $10 \%$ of the brunt of the wind on the conductors.

- The wind thrust on the support is approximated as if two adjacent faces of the support were exposed perpendicularly to the wind, cautiously neglecting the voids due to the reticular structure; the determined load is applied at different points so as to give the same resultant force.

The calculations were carried out assigning:

- $\quad$ Span length $=350 \mathrm{~m}$;

- $\quad$ Diameter of guard ropes $=0.0115 \mathrm{~m}$;

- $\quad$ Type of connection = ditching clamps;

- $\quad$ Conductor diameter $=0.0315 \mathrm{~m}$;

- 20 hood and pin insulators made of tempered glass for each pylon.

A TO was performed considering the most unfavorable LC to the model. With regard to Figure 11a, the worst conditions occur when the angle between the two adjacent spans (in green) is $120^{\circ}$ and one of the conductors (in red) is broken. This causes bending in the same wind direction.

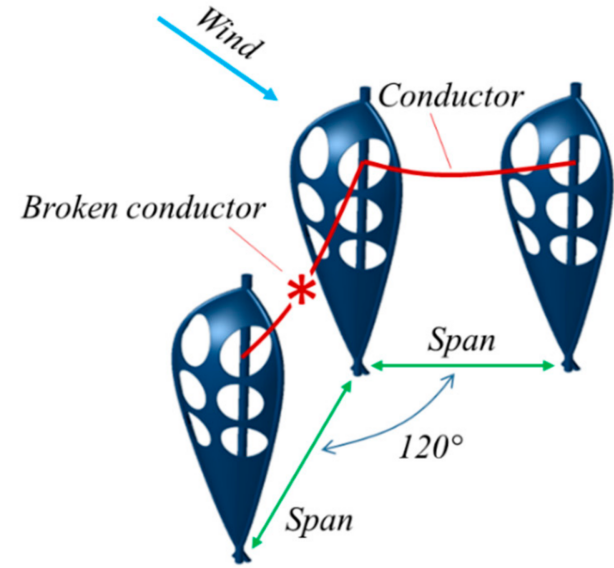

a

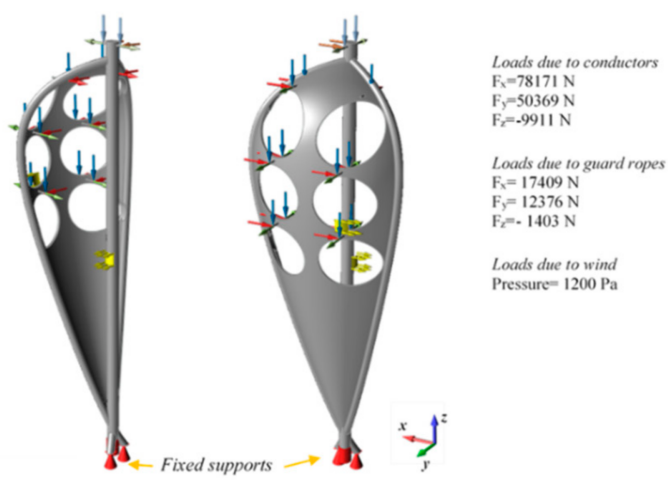

b

Figure 11. (a) The most unfavorable Load Condition (LC\#2), with two adjacent spans (in green) that form an angle of $120^{\circ}$, and a broken conductor; (b) boundary, constraints, and load conditions (common to all the three shapes).

Between the two LC of the standard that prescribe the breaking of a conductor (LC\#2 and LC\#4), LC\#2 is applied. Compared to LC\#4, it prescribes a higher wind speed and the absence of ice. This choice does not limit the result of the topological analysis; this analysis is expected to identify the optimal paths for the lines of force that cross the structure. The next engineering phase (see next subsection) will design in detail a structure that verifies all four LCs. The application of an asymmetrical load produces a model optimized only for unbalanced loads on one side. To solve this problem, in the optimization software the constraint of symmetry is imposed with respect to a user-defined plane.

The TO was performed by using the Altair Inspire®2018.3 software. In Figure 11b, the model, the constraints, and the loads for LC\#2 are summarized. In the case of very large shapes, the TO continues to be applicable, but to obtain a better result it is better to proceed incrementally.

The first step consists of considering the complete design volume (Figure 12, top row) and performing a TO for an initial reduction of material mass (Figure 12, bottom row, which shows TO 
models with only high-energy density elements, i.e., the elements that take part in carrying the loads). Table 9 collects the weight reduction after the first TO. Depending on the initial shape, this reduction is more than $50 \%$ for the stockier models (e.g., the Capestrano Warrior and the eagle models). For surface models (or thin thickness models), the reduction of material mass is much more limited, because the starting mass is consistently lower when compared to solid models. This is the case of the sail-shaped model, which consists of a mast (basically not reduced during the TO) and a sail, which is a thin thickness element: even if the percentage of mass reduction appears modest from Table 9, the model has been greatly lightened (Figure 12c).
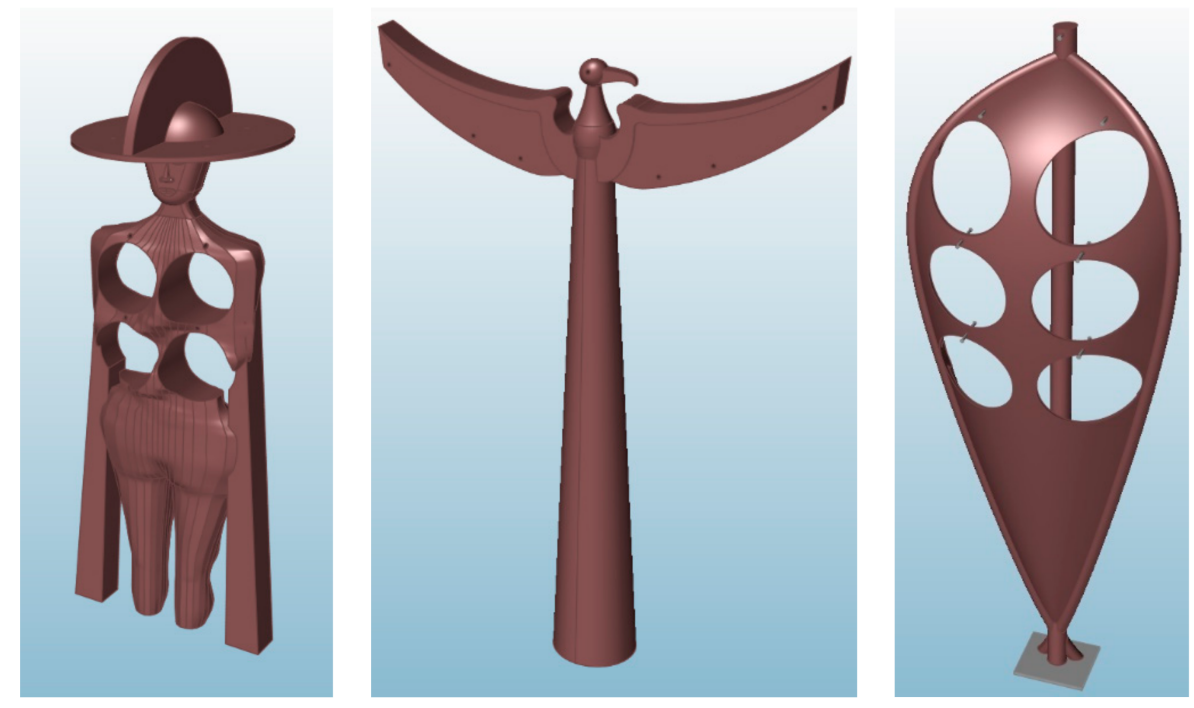

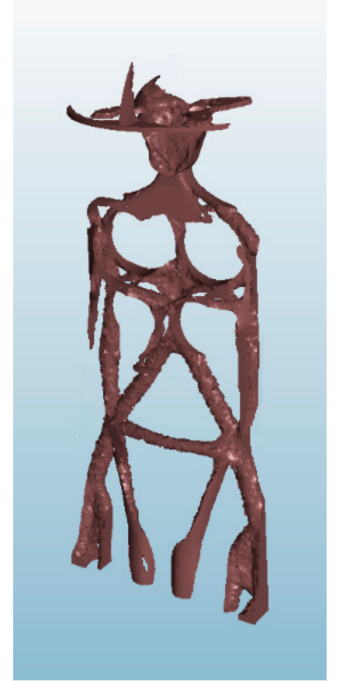

(a)

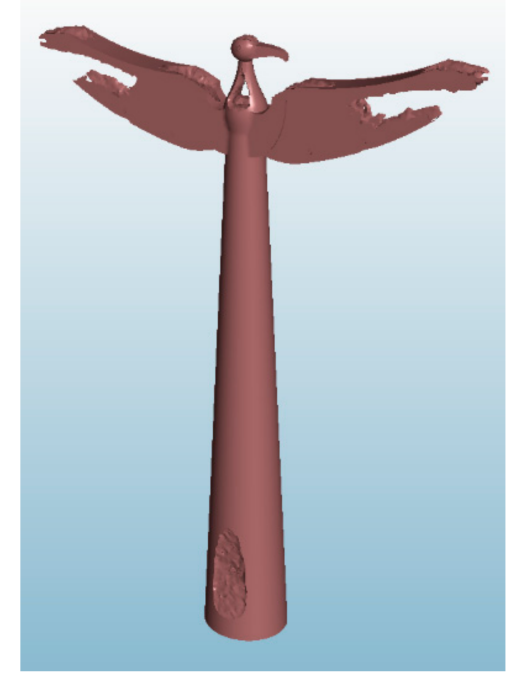

(b)

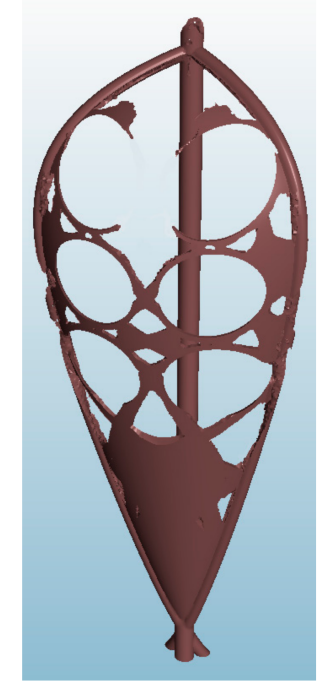

(c)

Figure 12. Topology optimization results: First weight reduction. (a) Capestrano Warrior statue; (b) Eagle; (c) Sail.

Table 9. Weight reduction after the first topology optimization.

\begin{tabular}{cccc}
\hline Weight & Warrior 380-kV & Eagle 380-kV & Sail 380-kV \\
\hline Initial weight (ton) & 2070 & 1913 & 1218 \\
Weight after the first reduction (ton) & 900 & 976 & 996 \\
Reduction factor (\%) & 56.5 & 49 & 18.2 \\
\hline
\end{tabular}


Figure 12a highlights a criticality in the Capestrano Warrior model: after the first weight reduction, the similarity with the starting form is lost.

This criticality emerges because the Capestrano Warrior presents a series of identification elements of small dimensions with respect to the macroscopic dimensions of the structure. As the TO process removes these small elements, the resemblance to the starting shape is no longer recognizable. Therefore, in order to maintain the resemblance to the starting shape, a lot of small details should be preserved and shaped by means of several lattice structures in the detail phase. This is not acceptable because these additional structures would increase excessively the final weight of the pylon, mitigating the optimization result. Therefore, we did not consider it more convenient to continue further with the design of this pylon.

Regarding the eagle and the sail-shaped models, the outputs of the previous phase (first weight reduction) suggest to apply further mass removal: therefore, each of them were modified and new project space was reconstructed (shown on the left side of Figure 13a,b). With particular respect to the eagle-shaped model, the first weight reduction suggests reducing the wings mass while the vertical support is not affected by any change. Therefore, with the aim to allow a further weight reduction during the second TO for enabling and exploring new designs of the vertical support, its upper diameter was slightly increased. Conversely, the mast in the sail-shaped model was not further modified since it was not the main design element to focus on; moreover, it is partially hidden by the sail, to which we addressed in our design efforts.

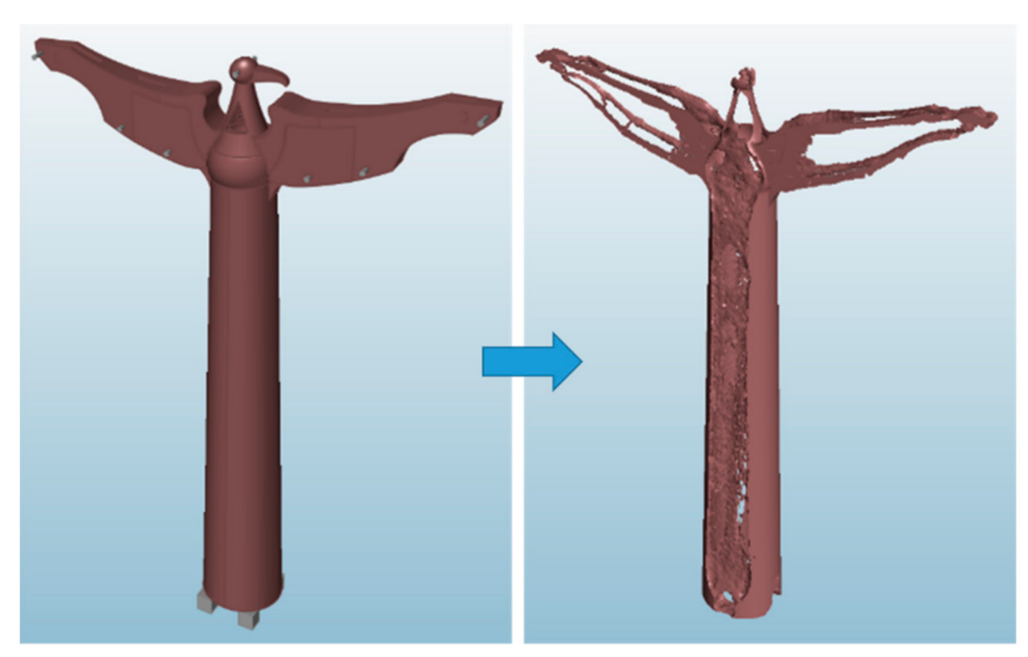

a

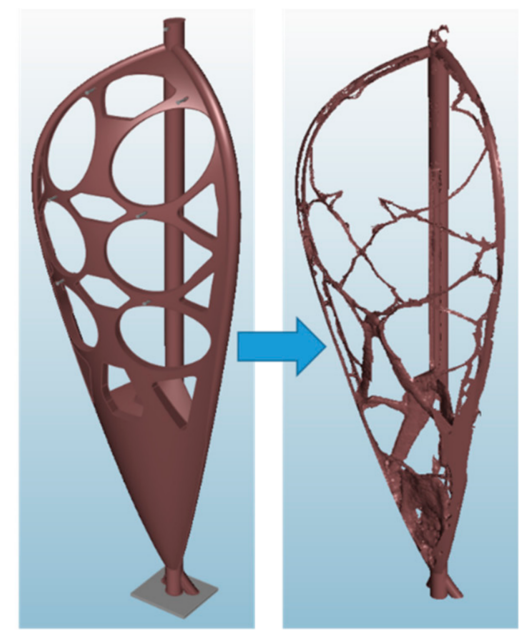

b

Figure 13. Updated 3D models and topology optimization results: final weight reduction. (a) Eagle (b) Sail.

The results of the second TO are shown on the right side of Figure 13a,b, which show TO models with both high- and low-energy density elements, i.e., the elements that have, respectively, a primary and a secondary role in carrying the loads.

The models resulting from the TO provide an indication of the path of the lines of force. In order to make the structure as light and less impactful as possible, the results of TO were approximated, manually, by a reticular structure (Figure 14). This phase requires expertise in structural design; however, the following phase driven by structural analysis allows further modification of the geometry, limiting the influence of errors due to this manual phase.

In each model, the main vertical support was discretized into a triangular reticular structure with a vertical axis, while the wings and the sail were delimited by reticular structures. Reinforcement elements were provided for the connection between the sail and the structure of the mast in the lower area. Finally, beams were inserted to support the six conductors. 


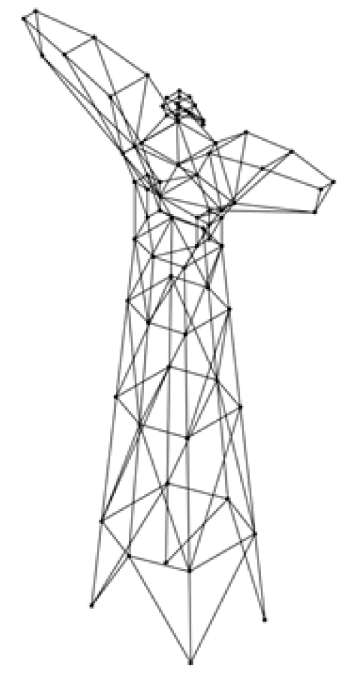

(a)

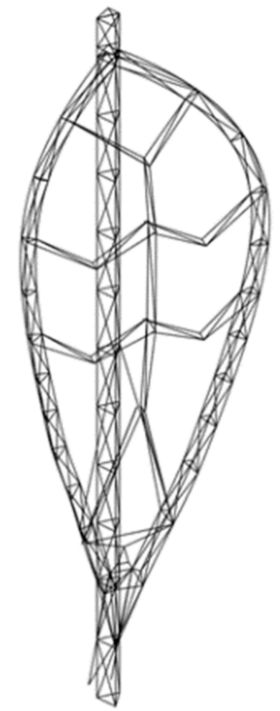

(b)

Figure 14. Initial reticular structure. (a) Eagle; (b) Sail.

\subsection{Detail Design}

The last design phase (detail design) requires developing the layout structure with standardized, commercial, or in any case easily achievable components. For the layouts of Figure 15, the design of the beams was carried out iteratively, imposing for each one a circular hollow section and the degree of slimness $\lambda \leq 15$ (according to the regulations) and verifying the structure with a Finite Elements Analysis (FEA) under the four loading conditions imposed by the regulations (LC\#1, LC \#2, LC \#3,

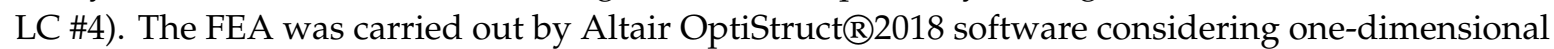
elements connected to each other in a rigid way, simulating threaded or welded couplings. Even if the standard imposes the degree of slimness of the beams, in the structural calculation a non-linear algorithm was imposed to take into account possible instability phenomena for peak loads according to Euler. Figure 15 shows the stress values and displacements for the final configuration under the four load hypotheses. The maximum stress values (obtained for LC\#2) are about one order of magnitude lower than the limit values for AISI 304.

The final pylons were engineered by assembling standard lattice components with bolted and welded connections. For the sail-shaped pylon, with the dual aim of protecting the welds and improving the aesthetic aspect, according to the results of the analyzed state-of-the-art, the reticular structures of the main mast and the sail were covered by sheet metal. Figure 16 shows the render of the lattice structure, with the final dimensioning of the beams of the elements of the mast, the sail, and the support for conductors. 


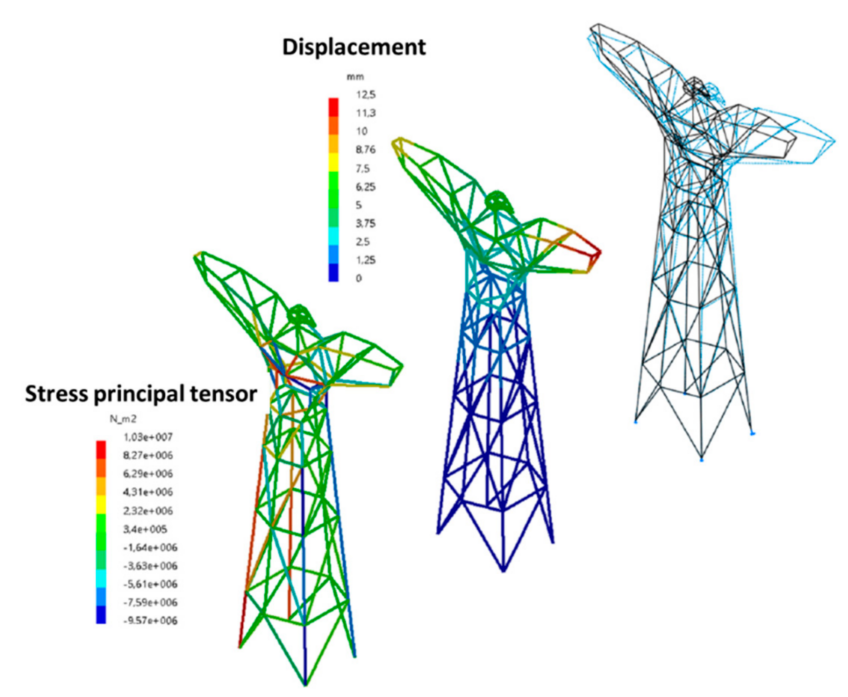

(a)

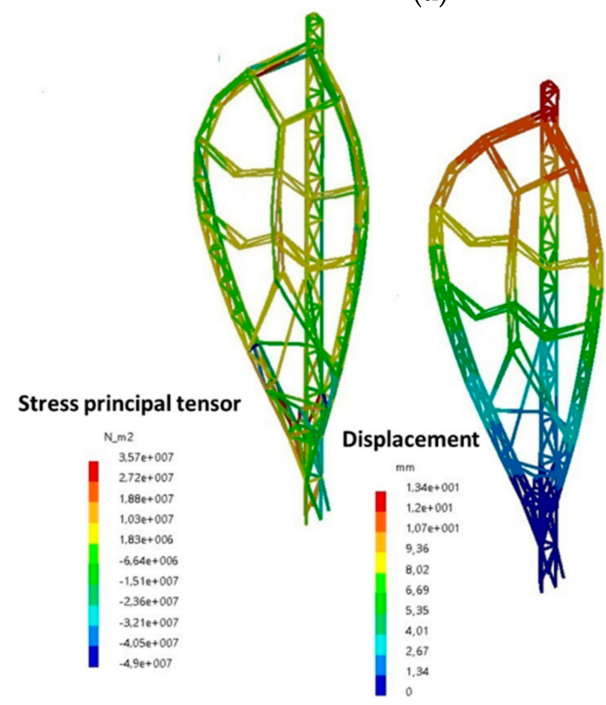

(b)

Figure 15. Results of Finite Elements Analysis (FEA) for the final configuration of the eagle (a) and sail (b) models under one of the load conditions (LC\#2).

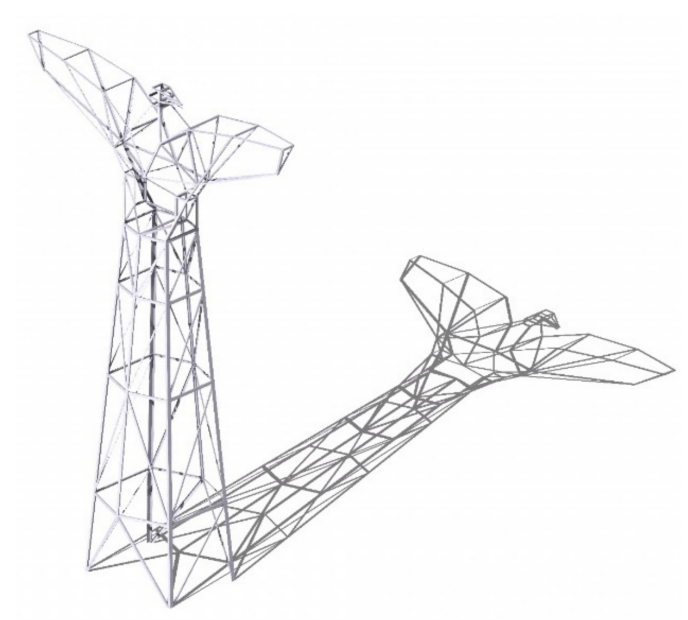

(a)

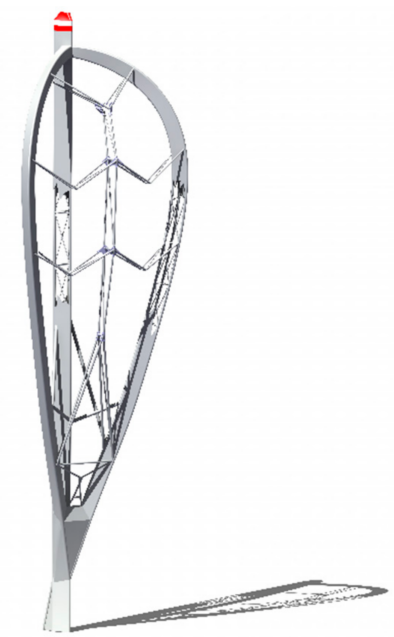

(b)

Figure 16. Render of the pylons final structures. (a) Eagle; (b) Sail. 


\subsection{Assessment of the Developed Pylons}

The method, applied to the territory of the Abruzzo region, leads to the definition of two new pylon designs that need to be assessed by citizen's preferences.

Similarly to Atkinson [2] and in accordance with [19], we defined and carried out a survey to investigate some options including the new pylon designs as well as the current design in the region. To this aim, renders of pylons placed in the internal (mountains) and coastal settings were prepared and shown to survey respondents, depending on their area of residence. Due to the Capestrano Warrior elimination, only people living in internal and coastal areas were asked to join the survey. Respondents were asked to express their preferences about the pylon designs, comparing the traditional pylon design with the new one (Figure 17). Specifically, the photographs of already installed HVPL pylons (shown at the top of Figure 17) were compared to the renders (shown at the bottom of Figure 17) of the new pylons. To this aim, we deleted the real pylon from the photographs and used these modified pictures as scenes for the renders.
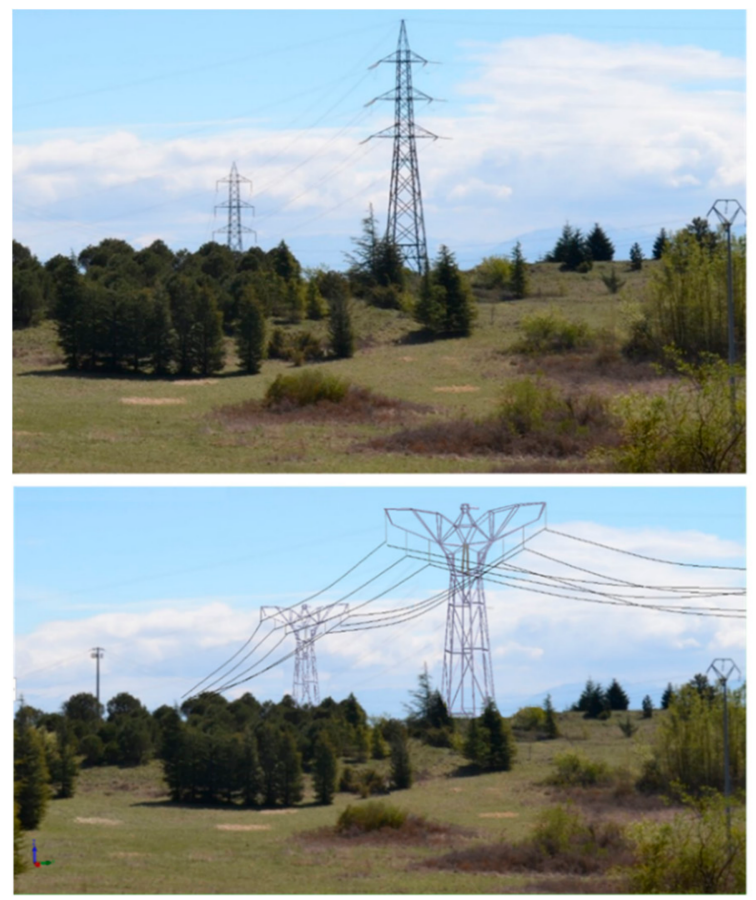

a
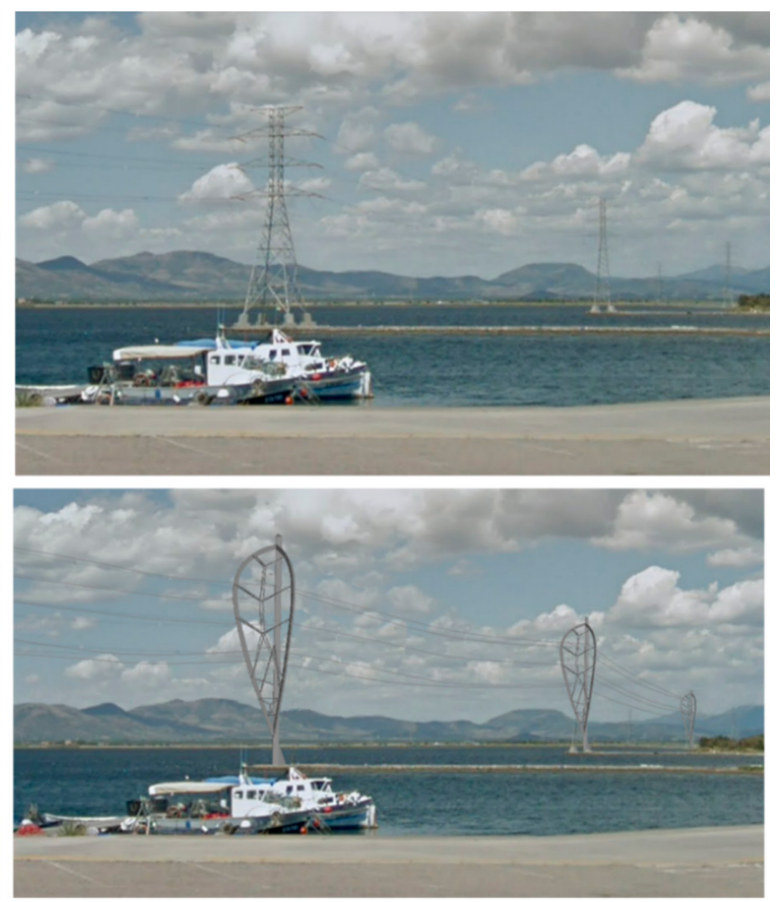

b

Figure 17. Traditional pylons (top) vs. renders of the developed eagle-shaped and sail-shaped pylons (bottom) in the internal (a) and coastal (b) landscape.

The survey respondents, whose sample characteristics are listed in Table 10, were 132 citizens between the ages of 18 and 65, divided into 63 men and 69 women, from different social backgrounds, mainly residents or tourists in the coastal area and in the internal area (which corresponds to the province of L'Aquila and the regional park of Velino-Silente).

The citizens were asked to compare the design and the visual appearance of the traditional pylon with the new one. In particular, survey respondents were asked: "Compare the visual appearance of these pylons within the internal or coastal landscape. Then, select one of them if preferable to the other, as well as none of them". The results are shown in Table 11. The analysis of the data suggests that both the new pylon designs best fit the landscape of the installation areas. 
Table 10. Sample characteristics.

\begin{tabular}{cccc}
\hline & & Coastal Area & Internal Area \\
\hline \multirow{2}{*}{ Total Number of Individuals } & $\mathbf{7 2}$ & $\mathbf{6 0}$ \\
\hline \multirow{2}{*}{ Demographic variables } & Males (\%) & $50.00 \%$ & $45.00 \%$ \\
& Average age (years) & 45 & 49 \\
\hline \multirow{2}{*}{ Education } & Middle school (\%) & $13.89 \%$ & $53.33 \%$ \\
& High school (\%) & $56.94 \%$ & $43.33 \%$ \\
& University (\%) & $29.17 \%$ & $3.33 \%$ \\
\hline \multirow{2}{*}{ Respondents' origin } & Residents living (\%) & $38.89 \%$ & $53.33 \%$ \\
& Tourists (\%) & $44.44 \%$ & $40.00 \%$ \\
& Others (\%) & $16.67 \%$ & $6.67 \%$ \\
\hline
\end{tabular}

Table 11. Citizens' preferences based on visual impact.

\begin{tabular}{cccc}
\hline Citizens & New Pylon Design & Traditional Pylon Design & None \\
\hline Coastal area (sail-shaped pylon) & $58.3 \%$ & $21.4 \%$ & $20.3 \%$ \\
Internal area (eagle-shaped pylon) & $56.5 \%$ & $19.7 \%$ & $23.8 \%$ \\
\hline
\end{tabular}

\section{Discussion}

The proposed method aimed to face the visual disamenity caused by the pylons of HVPL and similar vertical structures on the landscape. The design strategy originates from the weak points of the existing proposals of new pylons designs, which only partially comply with the requirements defined at the beginning of this research activity:

- Visual quality enhancement, as a possible approach to visual impact mitigation (compare [13,18,19]);

- Complete satisfaction of regulatory requirements and industrial feasibility.

Most examples of new pylon designs provided in the literature stopped at the conceptual phase [10]; they were not further developed into real applications due to many limitations (e.g., regulatory, safety, lack of feasibility, etc.). Conversely, in practice, we can find installed pylons with new designs that do not completely match the identified guidelines for mitigating the visual impact nor for visual quality enhancement.

To overcome these limitations, the proposed method includes both the previous two requirements, by systematically supporting the designers through the design steps. Again, the proposed method requires deep knowledge of the territory, from multiple points of view: landscape, natural environment, history, culture, and tradition. This may require the presence of a multidisciplinary team from the early planning stages.

The proposed design method was applied to a particularly critical situation: the design of a new electricity pylon for a 380-kV line to be installed into the territory of the Abruzzo region, a region with different landscape areas, as the coastal area, the mountains area, and natural reserves, but also with important cultural and historical cities. Applying the method to this critical situation, the following main limitations can be identified:

1. The method, in the current version, does not include the environmental assessment of such structures but is focused on the investigation of measures and principles regarding visual quality enhancement.

2. The method provides the generation of 3D models in the embodiment design phase with the support of a TO software. Even if the starting shapes are carefully selected, sometimes they may present criticalities, as in the case of the Capestrano Warrior, due to the presence of too many small characterizing details. In those cases, the designer is required to manually develop material reduction or to select a different starting shape. 
3. The method involves different kinds of skills and knowledge during the design process. In particular, the method involves citizens in the requirements collection phase, in the preference elicitation, as well in the final assessment phase. Similarly, due to the multidisciplinary skills and the multiple aspects required by the visual quality enhancement of pylons and similar structures, the design team may benefit of the inclusion of a landscape designer, an industrial designer, an expert in each of the disciplines corresponding to the criteria for the areas' subdivision (please refer to Section 3.2). This work, focused on the visual quality enhancement, involves a small but multidisciplinary team composed of mechanical engineers and designers, with the support of experts of the Abruzzo region (culture, tradition, geography, nature, etc.).

\section{Conclusions}

In this paper, a systematic method for the design of pylons with enhanced visual quality was presented. In order to reduce the visual disamenity of overhead electricity transmission lines, the proposed method starts from the early stages of the design process, in accordance with the main guidelines and suggestions coming from the literature review, involving local residents in the decision-making process, addressing natural, cultural, and historical references that soften the citizens' perceptions of the structures. Aiming at considering these guidelines together with all the other sources of requirements, the proposed method was based on the integration of morphological design and TO; hence, it consists of the following phases:

1. Identification of technical specifications, through analysis of the legislative and standard context, the environmental impact, the needs of visual receptors, and functional analysis;

2. Identification of a representative shape for the geographical area;

3. Development of a 3D CAD model of the pylon shaped according to the previous step;

4. TO of the 3D CAD model to define a geometry that is structurally efficient and at the same time respectful of the constraints imposed by the requirements previously identified;

5. Embodiment of the optimized 3D model into an industrial product able to be manufactured and installed but maintaining the features of the original shape.

As a result, the pylons satisfy all the technical specifications reported in Table 1, thanks to a lightweight structure engineered by means of a lattice structure, whose costs of manufacturing, installation, and maintenance, according to a qualitative assessment, should not exceed $20 \%$ of the current pylons. This extra cost of the new pylons is based on the expected linear dimensions of the trusses (extruded profiles) used for the final structures. Both the eagle-shaped and the sail-shaped models employ an extra $15 \%-20 \%$ of trusses when compared to the traditional design pylon. This increased the cost for materials (e.g., the extruded profiles), but also for the mechanical joints (e.g., fasteners or welding operations of the new structures). Moreover, the sail-shaped pylon could be partially covered by sheet metals, which may represent an additional cost.

In order to fully integrate a facility into the landscape, future efforts will be addressed towards more effective incorporation of the proposed method with visual impact mitigation principles. The method may be applied on the one hand to multiple installation areas by simply following the proposed workflow and, on the other hand, to different types of facilities as telecommunication antennas, wind turbines, road/railways bridges, and viaducts. To this aim, future developments will be concentrated on the application of the method to other structures and in other areas for which it is possible to identify symbolic shapes.

Author Contributions: Conceptualization, L.D.A. and F.G.; Investigation, P.D.S.; Methodology, L.D.A. and F.G.; Supervision, P.D.S. and F.L.; Writing—original draft, L.D.A. and F.G.; Writing—review \& editing, L.D.A., F.G., P.D.S. and F.L. All authors have read and agreed to the published version of the manuscript.

Funding: This research received no external funding.

Conflicts of Interest: The authors declare no conflict of interest. 


\section{References}

1. Koglin, J.H.; Gross, M. Representation of planned over headlines-The optical impression on the landscape. In Proceedings of the International Conference on Overhead Line Design and Construction: Theory and Practice, London, UK, 28-30 November 1988; pp. 151-155.

2. Atkinson, G.; Day, B.; Mourato, S. Underground or overground? Measuring the visual disamenity from overhead electricity transmission lines. In Environmental Valuation in Developed Countries: Case Studies; Pearce, D., Ed.; Edward Elgar Publishing: Cheltenham, UK, 2006; pp. 213-239.

3. Sumper, A.; Boix-Aragonès, O.; Villafáfila-Robles, R.; Bergas-Jané, J.; Ramírez-Pisco, R. Methodology for the assessment of the impact of existing high voltage lines in urban areas. Energy Policy 2010, 38, 6036-6044. [CrossRef]

4. Cotton, M.; Devine-Wright, P. Putting pylons into place: A UK case study of public perspectives on the impacts of high voltage overhead transmission lines. J. Environ. Plan. Manag. 2013, 56, 1225-1245. [CrossRef]

5. Navrud, S.; Ready, R.C.; Magnussen, K.; Bergland, O. Valuing the social benefits of avoiding landscape degradation from overhead power transmission lines: Do underground cables pass the benefit-cost test? Landsc. Res. 2008, 33, 281-296. [CrossRef]

6. United States Department of the Interior. Best Management Practices for Reducing Visual Impacts of Renewable Energy Facilities on BLM-Administered Lands; Bureau of Land Management: Cheyenne, WY, USA, 2013; 342p.

7. Reed, B. An Introduction to Visual Impact Assessment. Water, Engineering and Development Centre, School of Civil and Building Engineering Loughborough University: Leicestershire, UK, 2011. Available online: https://wedc-knowledge.lboro.ac.uk/resources/booklets/G001-Visual-impact-assessment-online.pdf (accessed on 3 February 2020).

8. Environmental Protection Department. HKSAR Landscape and Visual Impact Assessments, Chapter 6; Environmental Protection Department: Hong Kong, China, 2013. Available online: https://www.epd. gov.hk/eia/register/report/eiareport/eia_1852010/EIA/HTML/Rev\%20F_Sec\%206_html.htm (accessed on 3 February 2020).

9. Devine-Wright, P.; Batel, S. Explaining public preferences for high voltage pylon designs: An empirical study of perceived fit in a rural landscape. Land Use Policy 2013, 31, 640-649. [CrossRef]

10. Dapogny, C.; Faure, A.; Michailidis, G.; Allaire, G.; Couvelas, A.; Estevez, R. Geometric constraints for shape and topology optimization in architectural design. Comput. Mech. 2017, 59, 933-965. [CrossRef]

11. Frearson, A. New Pylons by Architect Erik Bystrup will "Become Part of the Landscape". Dezeen. Available online: https://www.dezeen.com/2015/06/02/new-t-pylon-erik-bystrup-united-kingdom-coutryside-morebeautiful-national-grid/2015 (accessed on 3 February 2020).

12. Priestley, T.; Evans, G.W. Resident perceptions of a nearby electric transmission line. J. Environ. Psychol. 1996, 16, 65-74. [CrossRef]

13. Countryside Agency and Scottish Natural Heritage. Landscape Character Assessment Guidance for England and Scotland; Natural England: Cheltenham, UK; Edinburg, TX, USA, 2002.

14. Foster and Partners ENEL Power Pylons. Available online: https://www.fosterandpartners.com/projects/ enel-power-pylons/2010 (accessed on 3 February 2020).

15. Image Title: "End of Line of T Pylons". Image Credits: Jonathan Thacker. Licensed for Reuse under Creative Commons Attribution-ShareAlike 2.0 Generic (CC BY-SA 2.0) Licence. Available online: https: //www.geograph.org.uk/photo/4456721 (accessed on 3 February 2020).

16. Image Title: "Freileitungsmast-Italien". Image Credits: Andreas Karrer. Licensed under the Creative Commons Attribution-Share Alike 4.0 International License. Available online: https://commons.wikimedia. org/wiki/File:Freileitungsmast-Italien.jpg (accessed on 3 February 2020).

17. Image Title: "Tralicci Foster". Image Credits: Terna SpA (Italy). Courtesy of Terna SpA (Italy). Available online: https://www.flickr.com/photos/ternaspa/13382864065 (accessed on 3 February 2020).

18. Landscape Institute and Institute of Environmental Management and Assessment. Guidelines for Landscape and Visual Impact Assessment, 3rd ed.; Routledge: New York, NY, USA, 2013.

19. Environmental Impact Statement Surat Gas Project. Coffey Environments 7040_04_Ch18_v3 18-30. Available online: https://www.arrowenergy.com.au/_data/assets/pdf_file/0009/28692/Chapter20182020Landscape20and20Visual20Amenity.pdf (accessed on 3 February 2020). 
20. Shea, K.; Smith, I.F. Improving full-scale transmission tower design through topology and shape optimization. J. Struct. Eng. 2006, 132, 781-790. [CrossRef]

21. Byrne, J.; Fenton, M.; Hemberg, E.; McDermott, J.; O’Neill, M. Optimising complex pylon structures with grammatical evolution. Inf. Sci. 2015, 316, 582-597. [CrossRef]

22. Guo, H.Y.; Li, Z.L. Structural topology optimization of high-voltage transmission tower with discrete variables. Struct. Multidiscip. Optim. 2011, 43, 851-861. [CrossRef]

23. Chen, J.; Yuan, F.; Jiang, L. Optimal design of transmission line tower based intelligent selection. In Proceedings of the Canadian Society for Mechanical Engineering International Congress, Toronto, ON, Canada, 3-7 June 2014.

24. De Souza, R.R.; Miguel, L.F.F.; Lopez, R.H.; Miguel, L.F.F.; Torii, A.J. A procedure for the size, shape and topology optimization of transmission line tower structures. Eng. Struct. 2016, 111, 162-184. [CrossRef]

25. Brütting, J.; Desruelle, J.; Senatore, G.; Fivet, C. Design of Truss Structures Through Reuse. Structures 2019, 18, 128-137. [CrossRef]

26. Gherardini, F.; Renzi, C.; Leali, F. A systematic user-centred framework for engineering product design in small- and medium-sized enterprises (SMEs). Int. J. Adv. Manuf. Technol. 2017, 91, 1723-1746. [CrossRef]

27. Camba, J.D.; Contero, M.; Company, P. Parametric CAD modeling: An analysis of strategies for design reusability. Comput. Aided Des. 2016, 74, 18-31. [CrossRef]

28. Urick, B.; Marussig, B.; Cohen, E.; Crawford, R.H.; Hughes, T.J.R.; Riesenfeld, R.F. Watertight Boolean operations: A framework for creating CAD-compatible gap-free editable solid models. Comput. Aided Des. 2019, 115, 147-160. [CrossRef]

29. Buonamici, F.; Carfagni, M.; Furferi, R.; Governi, L.; Lapini, A.; Volpe, Y. Reverse engineering modeling methods and tools: A survey. Comput. Aided Des. Appl. 2018, 15, 443-464. [CrossRef]

30. Zardin, B.; Borghi, M.; Gherardini, F.; Zanasi, N. Modelling and simulation of a hydrostatic steering system for agricultural tractors. Energies 2018, 11, 230. [CrossRef]

31. Nyirenda, P.J.; Bronsvoort, W.F. Numeric and curve parameters for freeform surface feature models. Comput. Aided Des. 2008, 40, 839-851. [CrossRef]

32. Bici, M.; Broggiato, G.B.; Campana, F. Topological optimization in concept Design: Starting approach and a validation case study. In Advances on Mechanics, Design Engineering and Manufacturing. Lecture Notes in Mechanical Engineering; Eynard, B., Nigrelli, V., Oliveri, S., Peris-Fajarnes, G., Rizzuti, S., Eds.; Springer: Cham, Switzerland, 2017.

33. López, C.; Baldomir, A.; Hernandez, S. The relevance of reliability-based topology optimization in early design stages of aircraft structures. Struct. Multidiscip. Optim. 2017. [CrossRef]

34. Müller, O.; Albers, A.; Ilzhöfer, B.; Häußler, P. Multidisciplinary shape and topology optimization and its integration in the product design process for the effective development of competitive products. Proc. Int. Conf. Eng. Des. 1999, 2, 655-670.

35. Kim, H.; Querin, O.M.; Steven, G.P. On the development of structural optimisation and its relevance in engineering design. Des. Stud. 2002, 23, 85-102. [CrossRef]

36. Pahl, G.; Beitz, W. Engineering Design: A Systematic Approach, 2nd ed.; Wallace, K.; Blessing, L.; Baurt, F., Translators; Springer: London, UK, 1996; pp. 125-143.

37. Hardie, G.J. Community participation based on three-dimensional simulation models. Des. Stud. 1988, 9, 56-61. [CrossRef]

38. Luck, R. Participatory design in architectural practice: Changing practices in future making in uncertain times. Des. Stud. 2018, 59, 139-157. [CrossRef]

39. Kempenaar, A.; van den Brink, A. Regional designing: A strategic design approach in landscape architecture. Des. Stud. 2018, 54, 80-95. [CrossRef]

(C) 2020 by the authors. Licensee MDPI, Basel, Switzerland. This article is an open access article distributed under the terms and conditions of the Creative Commons Attribution (CC BY) license (http://creativecommons.org/licenses/by/4.0/). 